\title{
Atmospheric correction of Earth-observation remote sensing images by Monte Carlo method
}

\author{
Hanane Hadjit*, Abdelaziz Oukebdane and Ahmad Hafid Belbachir \\ Laboratoire d'analyse et d'application du rayonnement (LAAR), Département de physique, \\ Université des Sciences et de la Technologie d'Oran, B.P. 1505, El M'nouar, Oran, Algerie. \\ *Corresponding author.e-mail: hhadjit75@yahoo.fr
}

In earth observation, the atmospheric particles contaminate severely, through absorption and scattering, the reflected electromagnetic signal from the earth surface. It will be greatly beneficial for land surface characterization if we can remove these atmospheric effects from imagery and retrieve surface reflectance that characterizes the surface properties with the purpose of atmospheric correction. Giving the geometric parameters of the studied image and assessing the parameters describing the state of the atmosphere, it is possible to evaluate the atmospheric reflectance, and upward and downward transmittances which take part in the garbling data obtained from the image. To that end, an atmospheric correction algorithm for high spectral resolution data over land surfaces has been developed. It is designed to obtain the main atmospheric parameters needed in the image correction and the interpretation of optical observations. It also estimates the optical characteristics of the Earth-observation imagery (LANDSAT and SPOT). The physics underlying the problem of solar radiation propagations that takes into account multiple scattering and sphericity of the atmosphere has been treated using Monte Carlo techniques.

\section{Introduction}

Radiometers on satellites measure the radiance reflected by earth and atmosphere. The simple calibration of the sensor, in radiance or reflectance, does not provide information on surface that is directly accessible but a composite signal which depends on atmospheric conditions (gas absorption, molecules and aerosols scattering) during measurements. The need of atmospheric correction is obvious. That is extracting, from the composite signal, information that depends only on the ground's surface being studied. As atmospheric effects become more quantitative, the retrieval of accurate surface reflectances becomes increasingly important. For instance, estimation of quantified surface properties is based on surface reflectance. LANDSAT and SPOT satellites are invaluable resources for monitoring global change. Then, the atmospheric correction is essential to adjust surface reflectance and calculate ground properties.

There is a relatively long history of the quantitative atmospheric correction of remote sensing imagery (Liang 2004). All methods reported in the literature can be roughly classified in three definite groups (Bonn et al. 2001): the methods based on the invariants whose principle is to suppose the existence, in the study zone, of surfaces which conserve their radiometric properties (deep water, roofs of buildings, etc.). Any change observed is, therefore, due to the atmospheric conditions. These methods require the identification of

Keywords. Atmospheric correction; reflectance; Monte Carlo method. 
a dark object (lakes, shades, etc.) within the image, estimation of the signal level over that object, and subtraction of that level from every pixel in the image (Ahern et al. 1977; Chavez 1989). The most used approaches are: Invariant-Object Method of Hall et al. (1991), Histogram Matching Method of Richter (1996), Dark-Object Method developed by Kaufman and Sendra (1988) and Contrast Reduction Methods of Tanre et al. (1988). The major weaknesses in this approach are in identifying a suitable object in a given scene, and once one is located, is the assumption of zero reflectance for that object (Teillet and Fedosejevs 1995). Also, the atmospheric correction can be conceded by simultaneous ground measurements, which makes it possible to find a direct relation between the digital accounts and the pixel radiance. This method is used in the update of satellite calibration curves. To allow a better statistical approach, this method requires a site where surface is most homogeneous and sufficiently large, which is not always obvious (Bonn et al. 2001).

A robust approach to the problem is to estimate atmospheric parameters of the image. The parameters can then be refined with any available ancillary measurements and iterative runs of an atmospheric modelling program to achieve consistency between the atmospheric parameters and the image data (Schowengerdt 2007). Estimation of atmospheric parameters from imagery itself is a difficult and challenging step, since atmospheric effects include molecular and aerosol scattering and absorption by gases. Molecular scattering and absorption are relatively easy to correct because of the stable concentrations of these elements over both time and space. The most difficult task is to estimate the spatial distributions of aerosols and water vapour directly from imagery (Liang 2004).

To retrieve surface reflectance, the effort must be focused on estimating the upward and downward atmospheric path radiance. One begins by calculating, from the image studied, the solar and observation geometric parameters. Then an atmospheric model is specified, that is the pressure and temperature profiles, and aerosol concentration and size. The calculation of extinction and scattering coefficients of atmosphere constituents (aerosols and molecules) is carried out. Then the probability of interaction for each constituent is determined. Once the geometrical and atmospheric parameters are calculated, the transport of the photons can be simulated inside the atmosphere using SART code (Spherical Atmosphere Radiation Transfer) (Hadjit 2007). Aerosols and molecules phase functions govern the scattering interactions between photons and atmospheric constituents.

The complexity and specificity of the problem being solved, impose the use of techniques based on analogue Monte Carlo. The path of a photon is constructed as follows:

An emitted photon at the top of the atmosphere is followed until its extinction. Between these two events, a number of diffusions can happen. Scattering changes the photon direction which is sampled from the phase functions. The history is terminated when absorption takes place.

Satellite images of different regions were used to implement the code SART which is designed to obtain the main atmospheric parameters needed in the correction such as the atmospheric reflectance, and the upward and downward transmittances. To confirm SART results, a comparative study with $6 \mathrm{~S}$ code was performed separately for molecular and aerosol atmospheres for various geometrical and atmospheric conditions. In addition, a comparison was made between the measured reflectances and calculated surface reflectances for different selected areas. To complete this study an image of the difference has been added for each study case in order to show the effect of image correction.

\section{Atmospheric model}

The atmospheric model and the physics related to the effects of the atmosphere have been assembled and converted into a photon transport code, namely the SART code which can track each generated photon. The use of Monte Carlo sampling techniques allows the determination of a number of parameters, mainly:

- The atmospheric reflectance, $\rho_{\text {atm }}$, which is a measure of the parasite signal. It can be evaluated by counting the number of scattered photons in the atmosphere;

- The downward transmittance, $T_{\text {tot }} \downarrow$, that is the number of photons transmitted to the ground's surface;

- The upward transmittance, $T_{\text {tot }} \uparrow$, that is the number of photons arriving at the ground's surface and deflected towards the sensor.

It is clear that atmospheric effects are the result of two processes: absorption and scattering exerted, simultaneously, by the two major components of the atmosphere namely gases and aerosols.

Absorption by gas molecules or aerosols results in the disappearance of photons and corresponds to the transformation of their energy into heat, hence a decrease in their number and a weakening of the measured signal.

The model goes thorough two major steps: the geometric and atmospheric parameter estimation and the surface reflectance retrieval. 


\subsection{Geometric and atmospheric parameters}

The geometrical parameters introduced in the model are calculated from data related to the remote sensing image being studied. The date, time of acquisition, line and column numbers of the pixel in the image enable us to calculate the zenith and azimuth angles of observation, as well as the solar angles $\theta_{s}$ and $\varphi_{s}$ (Vermote et al. 1997; Chami et al. 2001; Capderou 2005).

In the solar spectrum $(0.2-4 \mu \mathrm{m})$, the principal atmospheric gases responsible for absorption are: Oxygen $\left(\mathrm{O}_{2}\right)$, Ozone $\left(\mathrm{O}_{3}\right)$, water vapour $\left(\mathrm{H}_{2} \mathrm{O}\right)$ and Carbon dioxide $\left(\mathrm{CO}_{2}\right)$. Absorption by aerosols of anthropogenic origin, such as carbon soot, is higher than the most aerosols of natural origin (liquids, dust) but is generally lower than absorption by gases.

Rayleigh scattering, which is specified by the Rayleigh phase function, describes the scattering by gas molecules whose dimensions are very small compared to the photon wavelength. However, scattering by aerosol particles whose sizes are comparable to that of the wavelength is considered to be anisotropic according to Mie theory. The effect of interacting particles or molecules is measured by the attenuation (scattering or extinction) coefficients.

In our calculations, the extinction coefficient $k_{e}(z)$ was approximated by a step function. The total atmosphere layer of $100 \mathrm{~km}$ was divided into 33 sublayers or spheres with different step sizes. Each layer is defined by its temperature, pressure and a model that defines aerosol types and concentrations. SART use atmospheric data file representing the pressure and the temperature as a function of altitude for a standard atmosphere (USSTD76) (Thomas and Stamnes 1999).

Based on this, it is possible to calculate, for each layer, the corresponding attenuation coefficient as a function of the altitude $z$, given the attenuation coefficients of aerosols $\left(k_{\mathrm{att}, a}\right)$ and molecules $\left(k_{\text {att }, m}\right)$

$$
k_{\text {att }}(\lambda, z)=k_{\text {att }, a}(\lambda, z)+k_{\text {att }, m}(\lambda, z) .
$$

Aerosol attenuation coefficients depend on the photon wavelength $\lambda$ and altitude $z$, that is expressed by the following relation (Carr 2005):

$$
k_{\mathrm{att}, a}(\lambda, z)=s(z) \cdot k_{\mathrm{att}, a}(\lambda)
$$

$k_{\text {att }, a}(\lambda)$ is a scattering or extinction coefficient that depends on the wavelength according to Mie theory (Kondratyev 1969; Shettle and Fenn 1979; Hinds 1998; Kokhanovsky 2008), $s(z)$ is a scaling factor corresponding to extinction coefficient at $\lambda=550 \mathrm{~nm}$ and according to altitude: $s(z)=$ $k^{550}(z)=s(0) \cdot \exp \left(-z / H_{a}\right)$ where $H_{a}$ is aerosol scaling factor $\left(H_{a}=2 \mathrm{~km}\right)$, and $s(0)$ the extinction coefficient at surface related to the surface meteorological range $V$ via the Koschmieder formula (Koschmieder 1924; Gueymard and Kambezidis 1997; Carr 2005).

$$
s(0)=\frac{3.916}{V}-0.01159
$$

$V$ is defined as $V=1.306$ VIS, where VIS is the visibility given from the weather data.

Figure 1 shows the plots of aerosol extinction and scattering coefficients as a function of the wavelength, calculated by SART and $6 \mathrm{~S}$ codes. Scattering and extinction coefficients vary inversely with the wavelength.

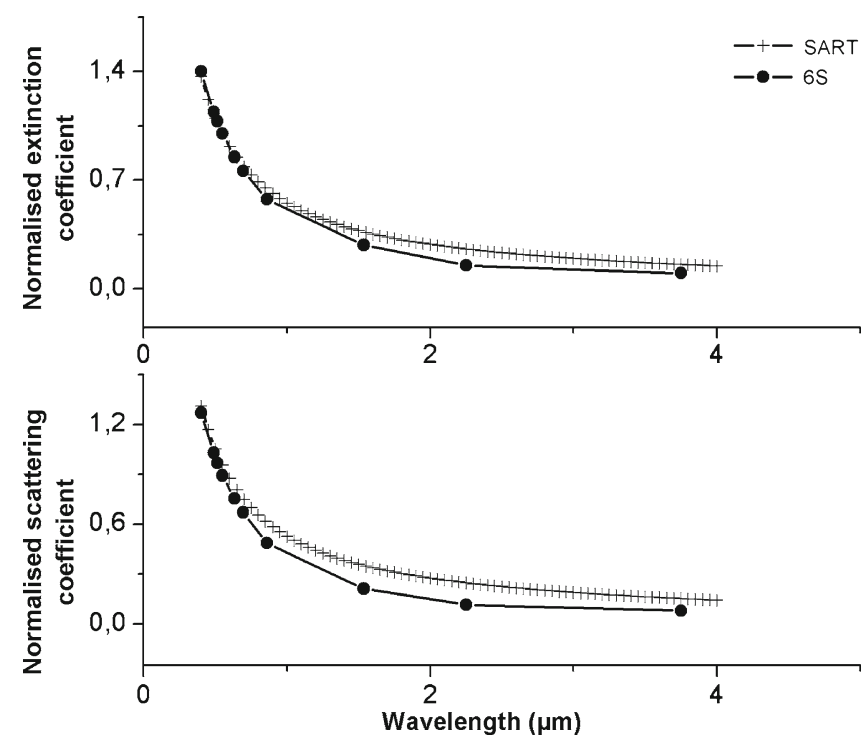

Figure 1. Extinction and scattering coefficients of aerosols as a function of wavelength.

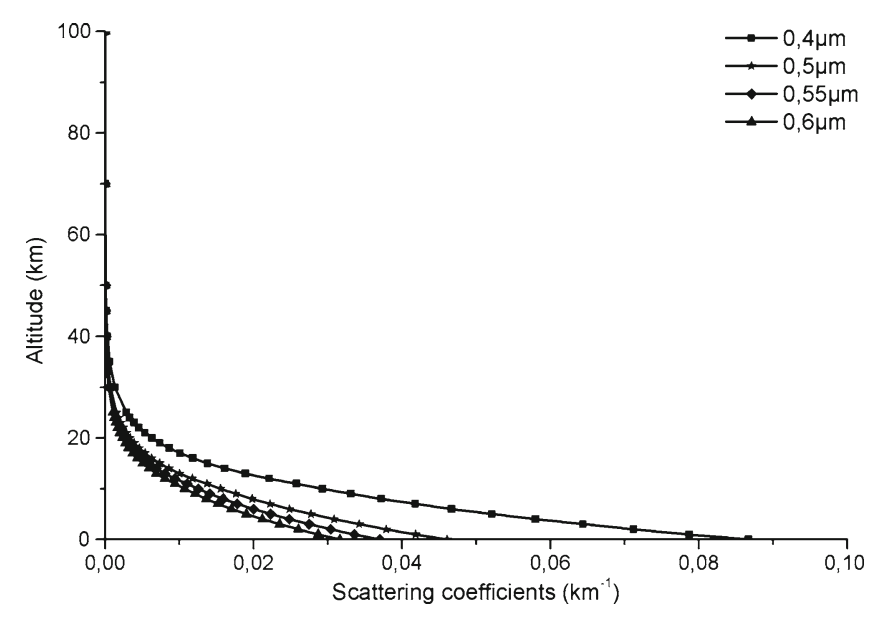

Figure 2. Scattering coefficient of molecules as a function of altitude. 
Molecular scattering coefficient is approximated by the following expression:

$$
k_{s, m}(z)=\sigma_{s} \cdot N_{r}(z) \cdot 10^{5}
$$

$\sigma_{s}$ is the scattering cross section (Rees 2001; Liou 2002) and $N_{r}(z)$ the molecular concentration $\left(\mathrm{cm}^{-3}\right)$ according to the pressure $P$, the temperature $T$ and the molecular density $N s(\mathrm{z}=0)=$ $2.5414310^{19}$ (Vermote et al. 1997).

$$
N_{r}(z)=N_{s} \frac{P(z)}{1013.25} \frac{273.15}{T(z)} .
$$

Since the scattering coefficients of molecules vary inversely with the altitude and the wavelength, they are negligible for the upper layers of the atmosphere because of the low concentration of atmospheric gases (figure 2).

However, the molecular extinction coefficient is calculated by taking into account the vertical molecule distribution in the atmosphere (CESBIO 2007).

$$
k_{e, m}(n)=\frac{\tau_{0}}{\Delta h}\left[\exp \left(-\frac{h_{n+1}}{H_{m}}\right)-\exp \left(-\frac{h_{n}}{H_{m}}\right)\right]
$$

$h_{n}$ and $h_{n+1}$ are lower and upper heights of layer $n, H_{m}$ is the molecular scale factor $\left(H_{m}=8 \mathrm{~km}\right)$, $\Delta h=h_{n+1}-h_{n}$ and $\tau_{0}$ is the total optical thickness of the atmosphere calculated using the total transmittance $T_{\text {tot }}$.

The total transmittance, dependent on the cosine of the solar zenith angle, the wavelength and weather data during image acquisition (pressure, temperature and humidity), is calculated using the modified Meteorological Radiation Model (MRM) (Bird and Riordan 1986; Psiloglou et al. 2000; Badescu 2008) for the region of Oran (Es-Senia: $35.38^{\circ} \mathrm{N}, 0.36^{\circ} \mathrm{W}$, height $=90 \mathrm{~m}$ ) and Mechria $\left(34.49^{\circ} \mathrm{N}, 0.62^{\circ} \mathrm{E}\right.$, height $\left.=1000 \mathrm{~m}\right)$ in Algeria,
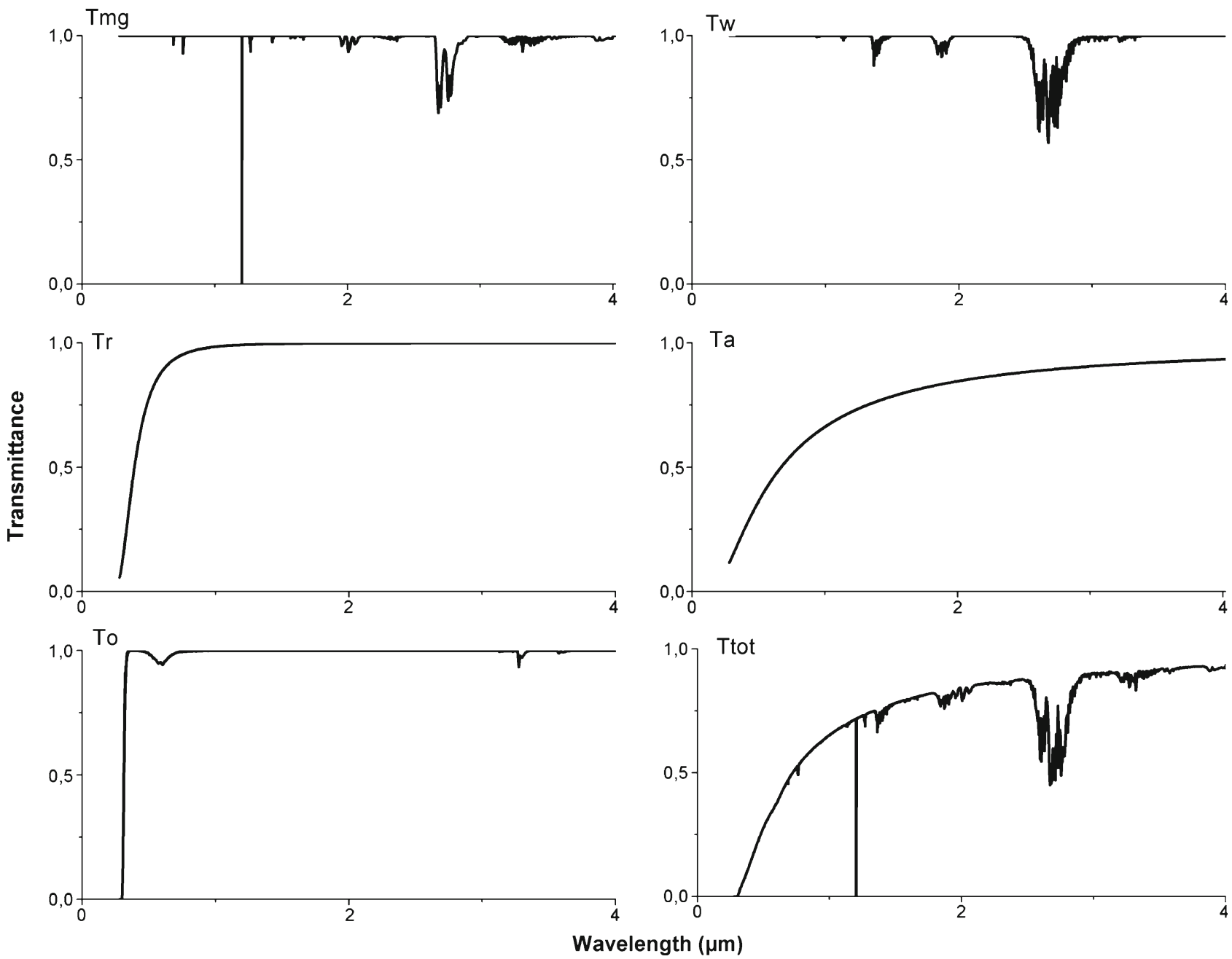

Figure 3. Transmittance as a function of wavelength. 
Quebec $\left(53.67^{\circ} \mathrm{N}, 66.86^{\circ} \mathrm{W}\right.$, height $\left.=600 \mathrm{~m}\right)$ in Canada and Railroad Valley Playa $\left(38.50^{\circ} \mathrm{N}\right.$, $115.69^{\circ} \mathrm{W}$, height $=1435 \mathrm{~m}$ ) in Nevada (USA). The total transmittance is defined as the product of Rayleigh transmittance.

$$
T_{r}=\exp \left\{-m_{r} /\left[\lambda^{4}\left(115.6406-1.335 / \lambda^{2}\right)\right]\right\},
$$

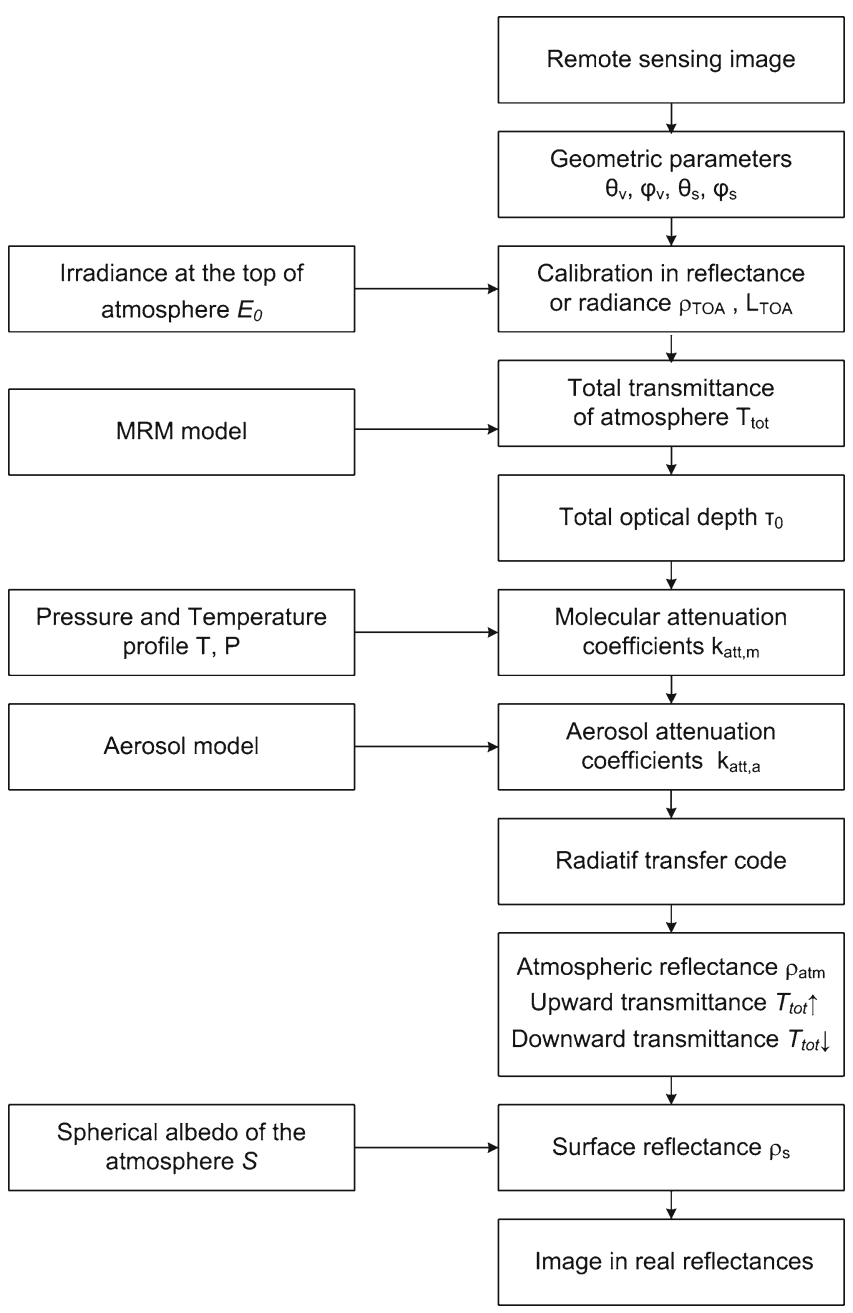

Figure 4. SART code diagram.

Table 1. Example of SART input and output parameters.

\section{Input data}

Image information: Satellite, image size

Geometric parameters $\left(\theta_{v}, \varphi_{v}, \theta_{s}, \varphi_{s}\right)$ : acquisition date and time, numbers of line and column

Atmospheric parameters: temperature, pressure, humidity, view point altitude, visibility

Spectral condition: wavelength

\section{Output parameters}

Total transmittance, total optical depth, spherical albedo, atmospheric reflectance and absorption, upward and downward atmospheric transmittance aerosol transmittance,

$$
T_{a}=\exp \left(-m_{a} \beta \lambda^{-1.3}\right),
$$

water vapour transmittance,

$$
\begin{aligned}
T_{w}= & \exp \left[-0.2385 a_{w}(\lambda) u_{w} m_{w}\right. \\
& \left./\left(1+20.07 a_{w}(\lambda) u_{w} m_{w}\right)^{0.45}\right],
\end{aligned}
$$

mixed gas transmittance,

$$
\begin{aligned}
T_{m g}= & \exp \left[-1.41 a_{m g}(\lambda) m_{m g}\right. \\
& \left./\left(1+118.93 a_{m g}(\lambda) m_{m g}\right)^{0.45}\right]
\end{aligned}
$$

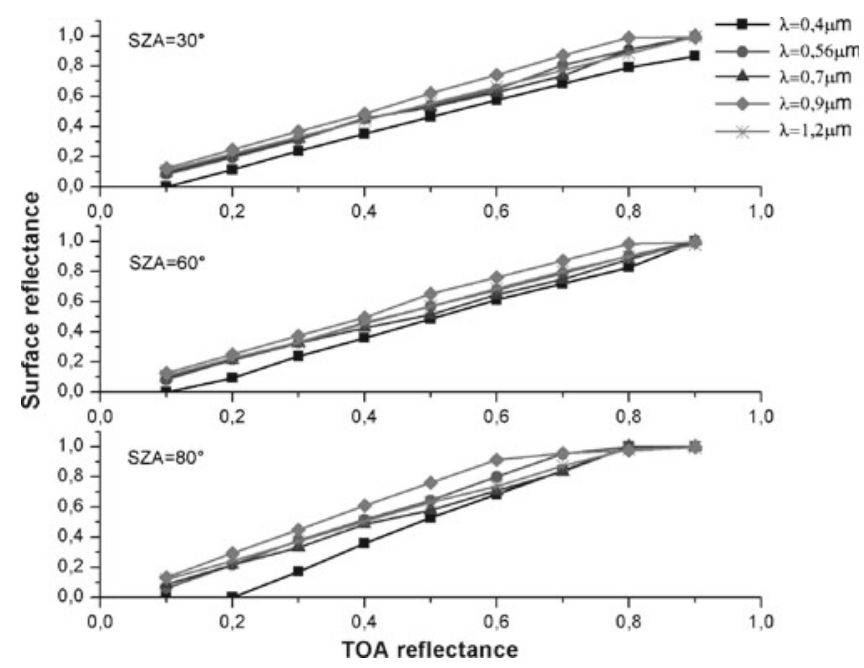

Figure 5. Surface reflectance calculated by SART according to top of atmosphere reflectance (TOA) for a molecular atmosphere.

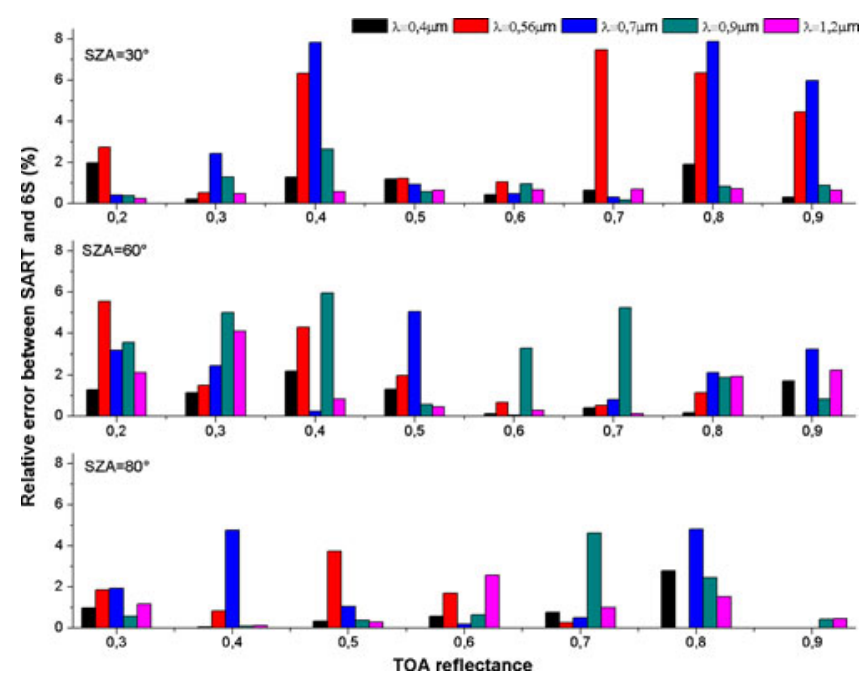

Figure 6. Relative error in absolute value between reflectances calculated by $6 \mathrm{~S}$ and SART codes (molecular atmosphere). 
and ozone transmittance,

$$
T_{o}=\exp \left(-a_{o}(\lambda) u_{o} m_{o}\right),
$$

where $m_{a}, m_{o}$ and $m_{w}$ are the aerosol, the ozone and the water vapour optical masses respectively (Gueymard and Kambezidis 1997), $m_{r}$ and $m_{m g}$ are the pressure corrected airmasses of Rayleigh and mixed gas (Iqbal 1983), $u_{o}$ and $u_{w}$ are, in that order, the ozone amount and the precipitable water in vertical path (Leckner 1978; Van Heuklon 1979; Koussa et al. 2006; Badescu 2008), $\beta$ is the Angstrom coefficient and $a_{o}, a_{w}$ and $a_{m g}$ are the spectral absorption coefficients of ozone, water vapour and mixed gas (Gueymard 1995).

Figure 3 shows Rayleigh $\left(T_{r}\right)$, Ozone $\left(T_{o}\right)$, water vapour $\left(T_{w}\right)$, gas mixture $\left(T_{m g}\right)$, aerosol $\left(T_{a}\right)$ and total $\left(T_{\text {tot }}\right)$ transmittances calculated according to the wavelength for Oran region. In the visible and near-infrared, atmosphere is practically transparent to electromagnetic radiation except for few absorption bands (1.2 and $2.7 \mu \mathrm{m})$ due to gas and water vapour absorption.
The photon trajectory in atmosphere, which is a sequence of broken lines, can be specified by a series of three spatial coordinates $\left(x_{i}, y_{i}, z_{i}\right)$, $i=1,2, \ldots, n$. These coordinates determine the site of the $i$ th interaction between photon and atmospheric constituents.

In order to calculate the free path length $l_{i}$, that is the distance in $\mathrm{km}$ between two interaction sites, it might be convenient to use a dimensionless quantity, i.e., the optical depth $\tau_{i}$ which can be randomly sampled from an exponential distribution, then converted into a real distance using extinction coefficients (equation 6):

$$
\tau_{i}=\int_{0}^{l_{i}} k_{e}(z) d z .
$$

Once $\tau_{i}$ is calculated, the layer index $j$ is found by resolving the following double inequality:

$\sum_{j=1}^{n-1} k_{e j}\left(l_{i, j+1}-l_{i, j}\right)<\tau_{i}<\sum_{j=1}^{n} k_{e j}\left(l_{i, j+1}-l_{i, j}\right)$
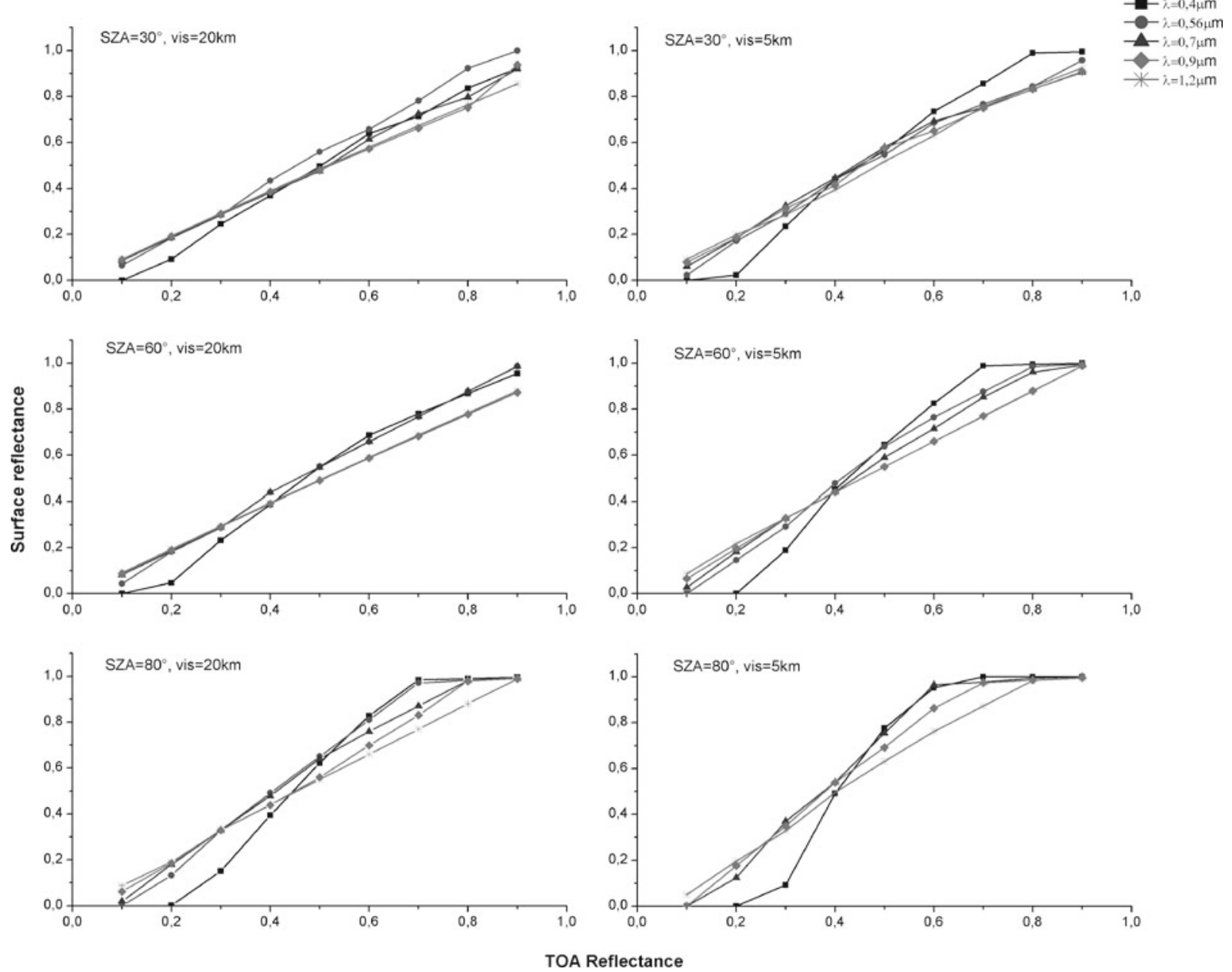

Figure 7. Surface reflectance calculated by SART according to TOA reflectance for an aerosol atmosphere (biomass burning model). 
where $l_{i, j}$ is the distance from the interaction site $\left(x_{i}, y_{i}, z_{i}\right)$ to the boundary of the spherical layer of index $j$, and $k_{e j}$ is the total extinction coefficient of layer $j$ previously calculated. To find $l_{i}$, equation (7) can be reformulated as follows:

$$
l_{i}=l_{i, n}+\left[\frac{\tau_{i}-\sum_{j=1}^{n-1} k_{j}\left(l_{i, j+1}-l_{i, j}\right)}{k_{n}}\right] .
$$

In order to determine the type of interaction, a random number is compared to the scattering probability $\omega_{p}=k_{s} / k_{e}$ at point $\left(x_{i}, y_{i}, z_{i}\right)$ and a decision is taken regarding the realization of a given interaction. In the same way, the scattering kind (by aerosols or molecules) is given by using aerosol scattering probability defined as the rapport between aerosol scattering and total scattering coefficients.
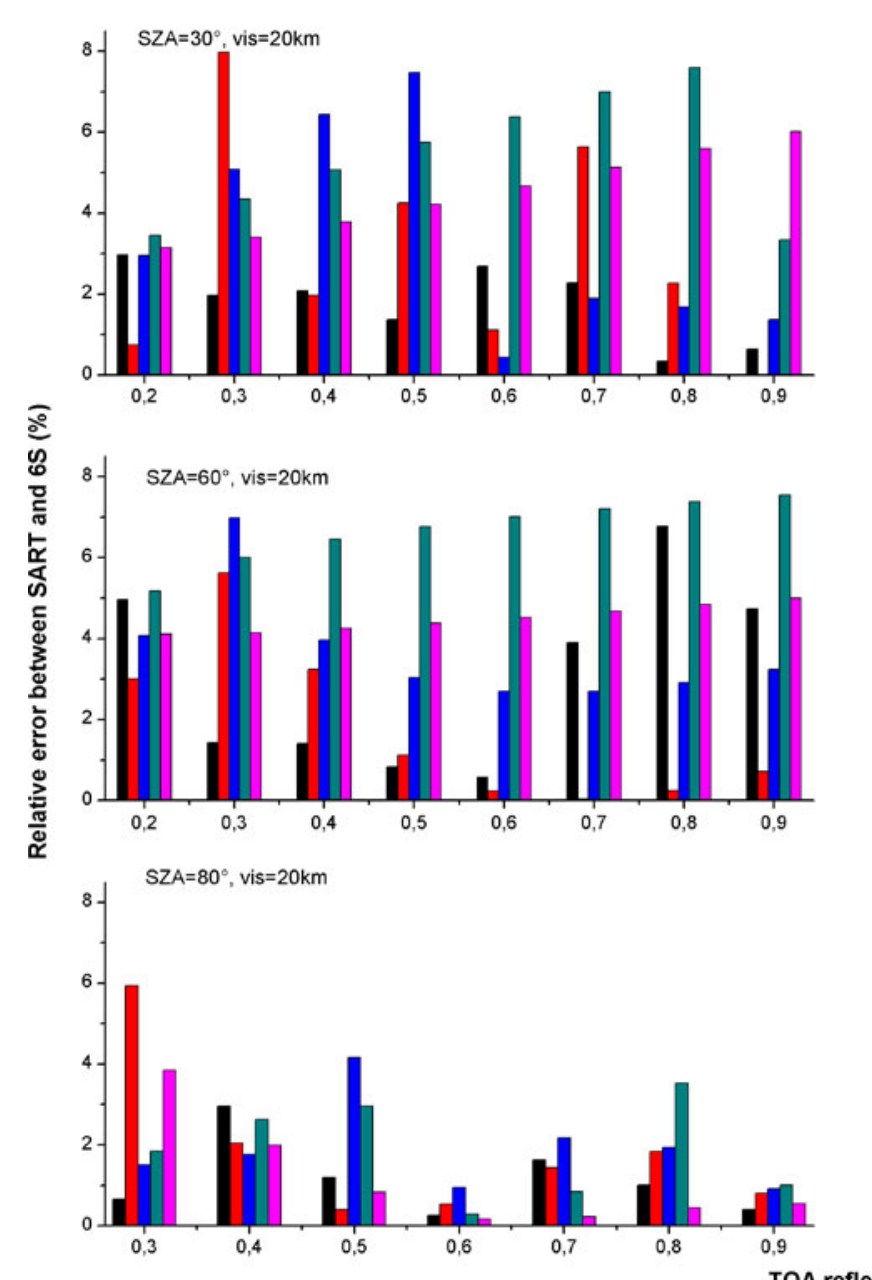

After a scattering event, the new photon direction is defined by the scattering angle $\theta_{i}$ and the azimuth angle $\varphi_{i}$. A set of two phase function is used, depending on the type of the particle involved in the interaction. In the case of scattering by atmospheric molecules, the Rayleigh phase function is used (Vermote et al. 1997).

$$
P\left(\theta_{i}\right)=\frac{3}{4} \cdot \frac{2(1-\delta)}{2+\delta}\left[1+\cos ^{2}\left(\theta_{i}\right)\right]
$$

where $\delta=0.0279$ is the depolarization factor which takes into account the anisotropy of molecular scattering.

In the case of scattering by aerosols, the phase function of Henyey-Greenstein is used to describe the diffusion angle (Kokhanovsky 2008). However, the modified Henyey-Greenstein function $P\left(\theta_{i}, a, g_{1}, g_{2}\right)$ is used in our code SART to
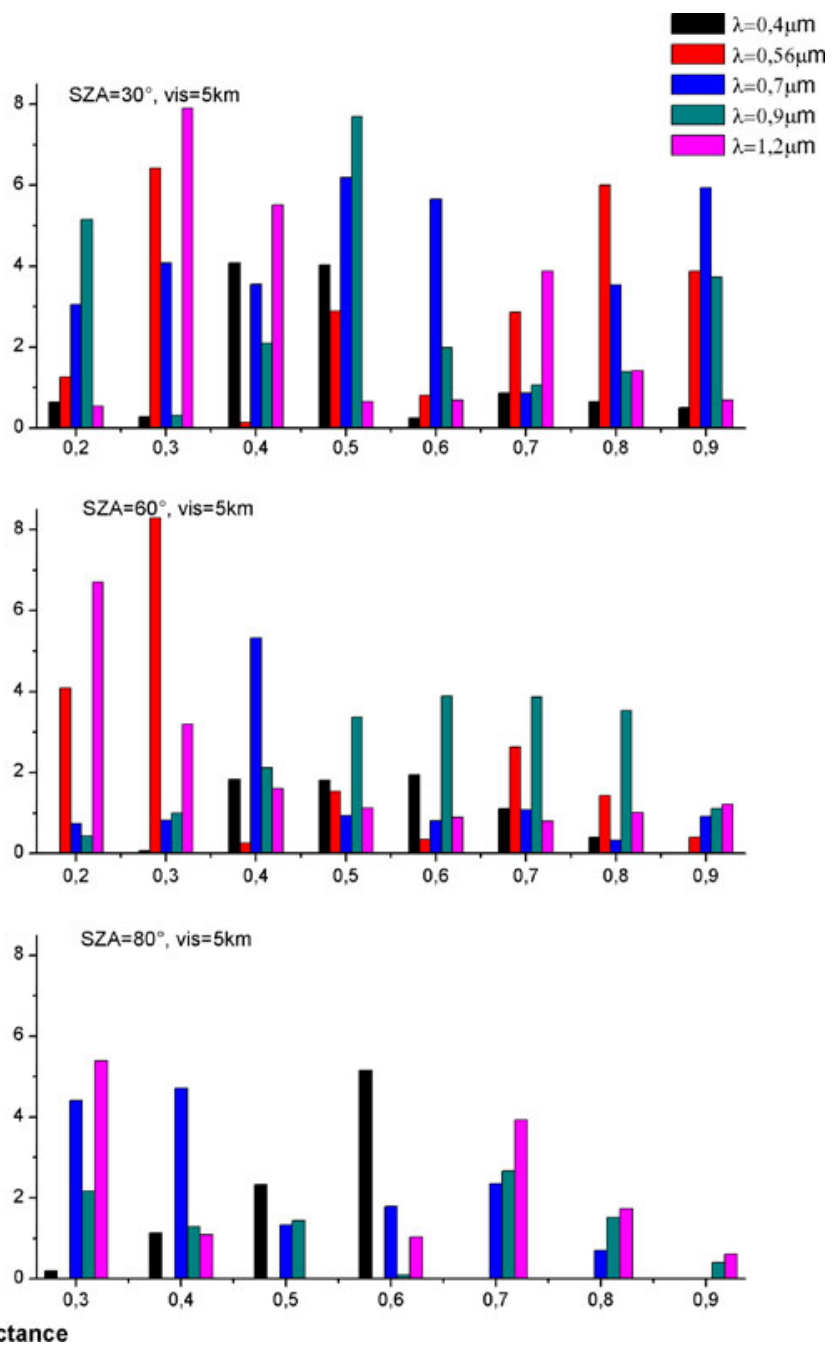

Figure 8. Relative error between reflectances calculated by $6 \mathrm{~S}$ and SART codes for an aerosol atmosphere (biomass burning model). 
model the maximum forward scatter and the local maximum backscatter (used also in DART) (Gascon 2001):

$$
\begin{aligned}
P\left(\theta_{i}, a, g_{1}, g_{2}\right)= & \frac{a\left(1-g_{1}^{2}\right)}{\left[1+g_{1}^{2}-2 g_{1} \cos \left(\theta_{i}\right)\right]^{1,5}} \\
& +\frac{(1-a)\left(1-g_{2}^{2}\right)}{\left[1+g_{2}^{2}-2 g_{2} \cos \left(180-\theta_{i}\right)\right]^{1,5}} .
\end{aligned}
$$

The parameter $a$ and the asymmetry factors $g_{1}$ and $g_{2}$ depend on the size distribution of aerosols and wavelength $\lambda$. In the current version of SART, the parameters $a, g_{1}$ and $g_{2}$ are constants whose numerical values are $0.95,0.79$ and 0.4 , respectively. The Monte Carlo techniques are used to sample $\theta_{i}$ and $\varphi_{i}$. The scattering angle $\theta_{i}$ is given by sampling either the aerosol or molecule phase functions using inversion numerical process. However, the rejection method is used to calculate $\cos \varphi_{i}$ and $\sin \varphi_{i}$ using a uniform distribution on $[0,2 \pi]$ (Marchuk and Mikhailov 1980).
Thus, the new position of the interaction site is deduced from the old position, the directional angles and the free path $l_{i}$.

\subsection{Surface reflectance determination}

The signal arriving at the sensor (radiometric signal) is more or less contaminated by a noise signal which is partly due to the atmospheric scattering. As a result, the radiometric signal depends on the surface characteristics, the incident irradiance and the atmospheric effects. The relation of Kaufman and Sendra (1988) and Fraser et al. (1992) expresses the measured radiance $L_{\mathrm{TOA}}$ as a function of the surface reflectance $\rho_{s}$ as well as other parameters:

$$
L_{\mathrm{TOA}}=\frac{\rho_{s} T_{\mathrm{tot}} \downarrow T_{\mathrm{tot}} \uparrow E_{0}}{\pi\left(1-S \rho_{s}\right)} \cos (\theta)+L_{\mathrm{atm}}
$$

where $T_{\text {tot }} \uparrow$ : upward atmospheric transmittance; $T_{\text {tot } \downarrow}$ : downward atmospheric transmittance; $L_{\text {atm }}$ : atmospheric radiance; $S$ : spherical albedo of the
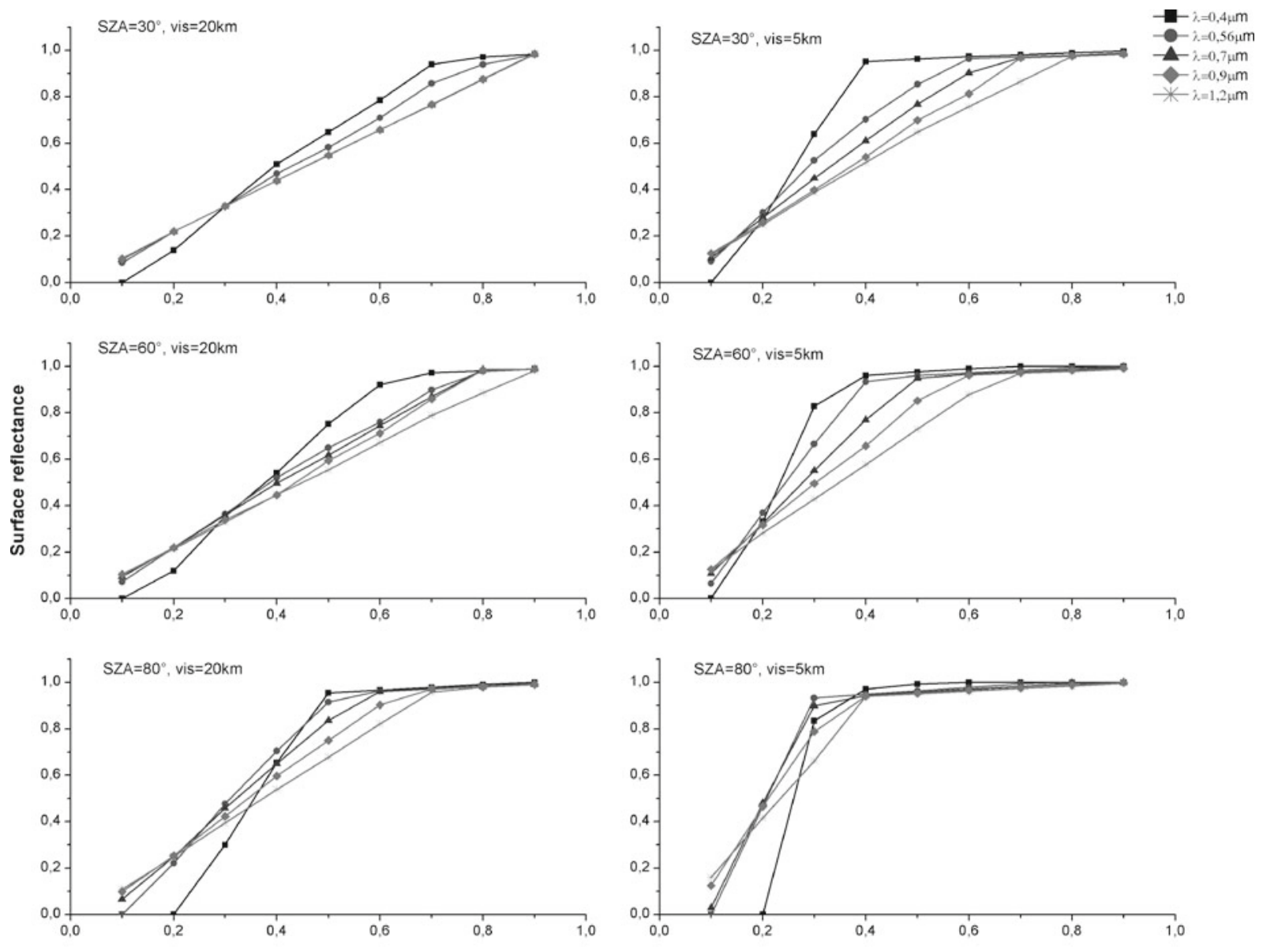

TOA reflectance

Figure 9. Surface reflectance calculated by SART according to TOA reflectance for an aerosol atmosphere (urban model). 
atmosphere; and $E_{0}$ : irradiance at the top of atmosphere.

Radiances are transformed into reflectances $\rho$ as follows (Bonn et al. 2001):

$$
\rho=\frac{\pi L}{\cos (\theta) E_{0}}
$$

Leading to:

$$
\rho_{s}=\frac{\rho_{\mathrm{TOA}}-\rho_{\mathrm{atm}}}{T_{\mathrm{tot}} \downarrow T_{\mathrm{tot}} \uparrow+S\left(\rho_{\mathrm{TOA}}-\rho_{\mathrm{atm}}\right)}
$$

$\rho_{\mathrm{TOA}}$ being the reflectance measured at the sensor level, $\rho_{\text {atm }}$ the atmospheric reflectance and $\rho_{\mathrm{s}}$ the surface reflectance which is the parameter being sought.

An adequate radiative transfer model is capable of determining not only atmospheric reflectances but also upward and downward transmittances.
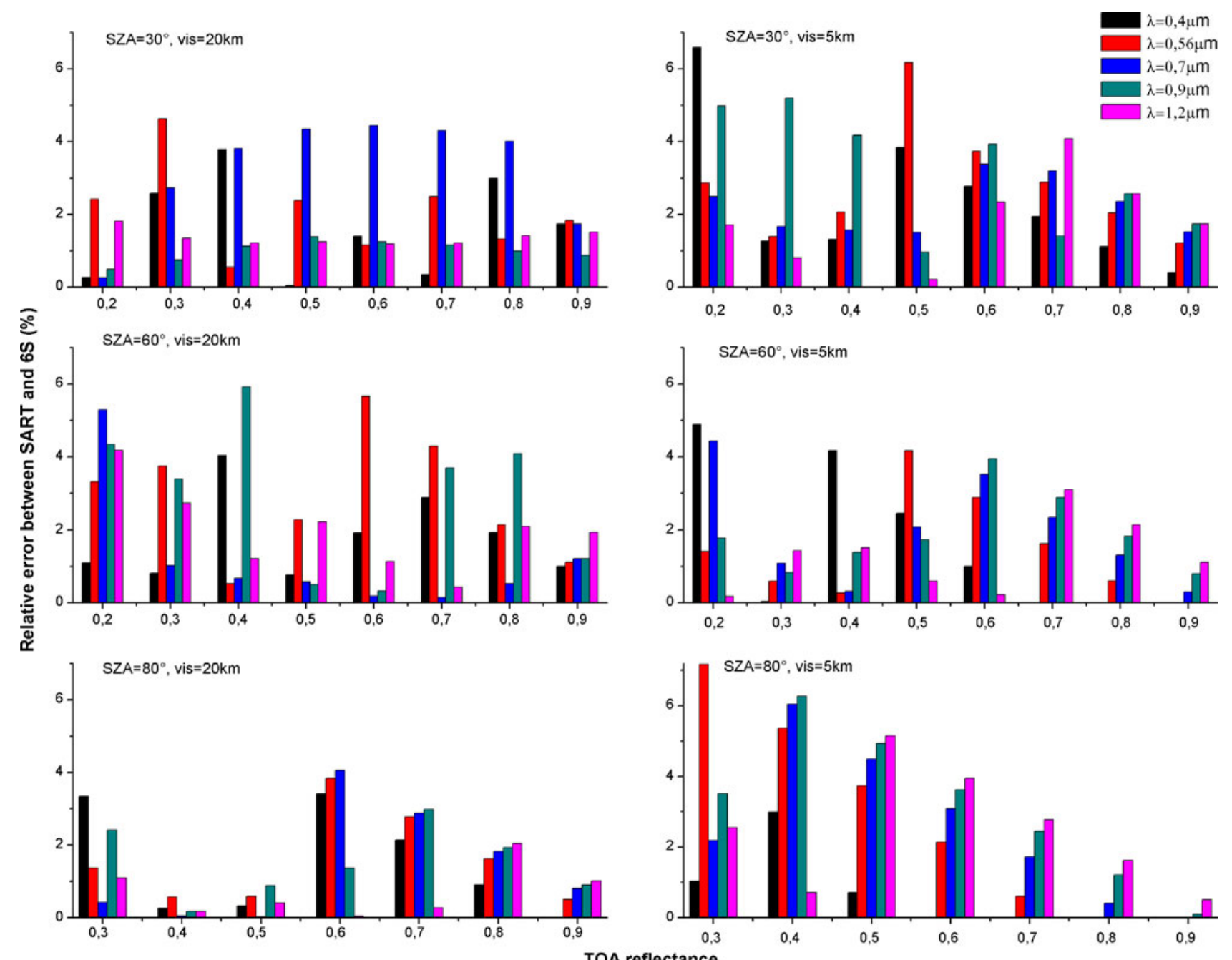

TOA reflectance

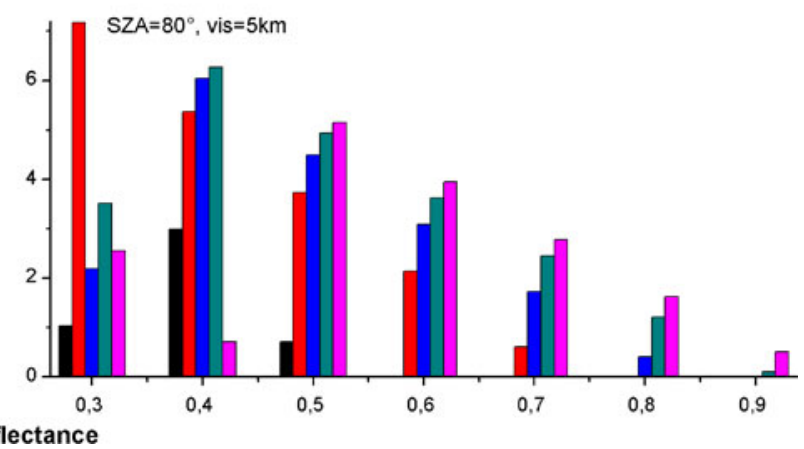

Figure 10. Relative error between reflectances calculated by $6 \mathrm{~S}$ and SART codes for an aerosol atmosphere (urban model). 

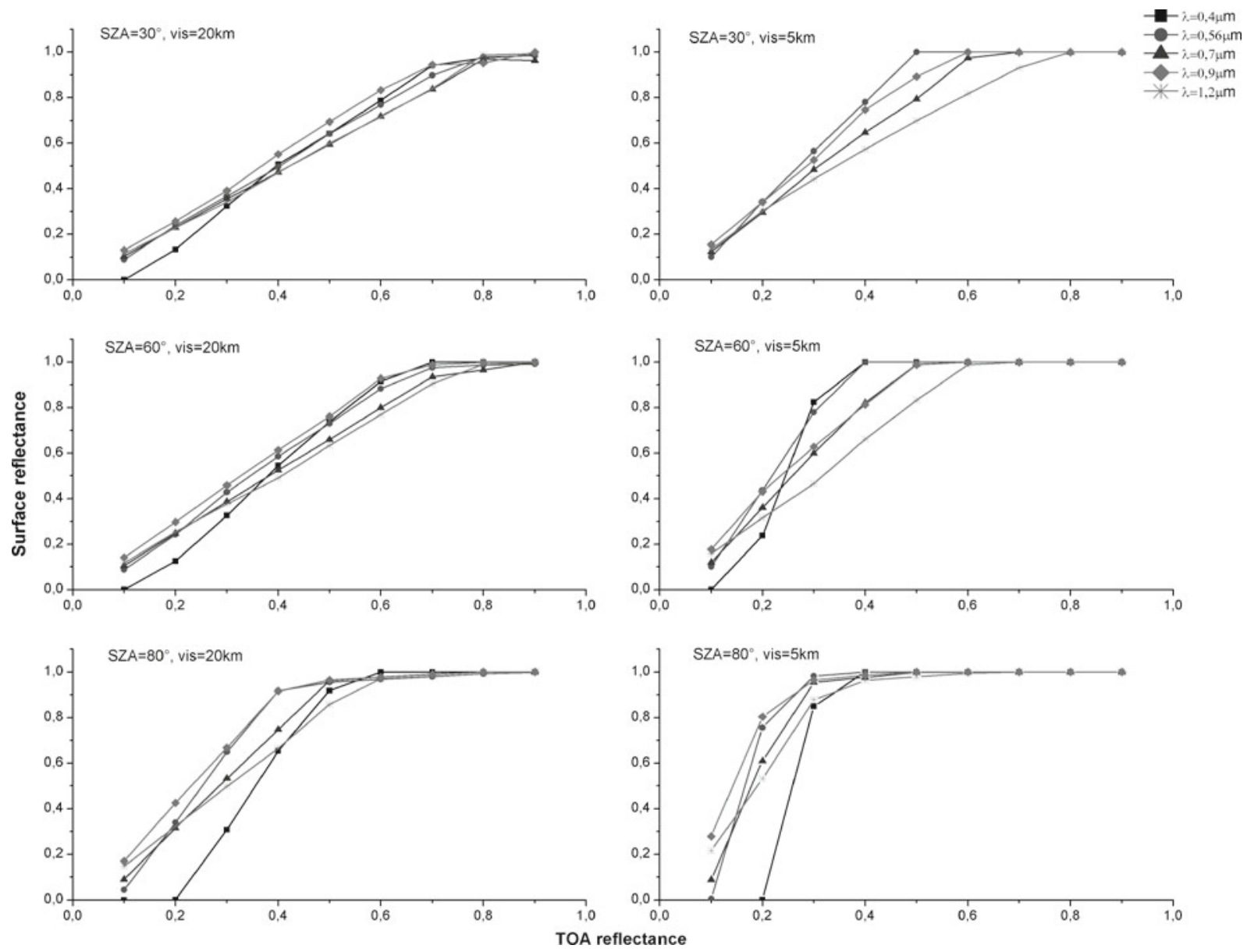

Figure 11. Surface reflectance calculated by SART according to TOA reflectance for a mixed atmosphere (US standard and urban model).

the results obtained by SART code, a comparison was carried out with $6 \mathrm{~S}$ code. The official website of $6 \mathrm{~S}$ code (http://6s.ltdri.org) yields, online, the correction coefficients converted into reflectances (Vermote et al. 1997).

The study was made for TOA reflectances varying from 0.1 to 0.9 under various atmospheric and geometrical conditions and for several monochromatic wavelengths. The surface reflectances calculated by SART and $6 \mathrm{~S}$ codes are compared. Three cases are studied: the first exploit a molecular atmosphere for various solar angles. Figure 5 represents the SART surface reflectances for a standard US atmosphere for several wavelengths $\lambda$.

The graphs show that the surface reflectance increases linearly with TOA reflectance to reach a limit value of 1 . Also, the surface reflectance increases, contrary to TOA reflectance, when the wavelength increases except for $\lambda=1.2 \mu \mathrm{m}$ because of the strong absorption by gases.

The relative error $\varepsilon_{r}$, expressed as a percentage between SART and $6 \mathrm{~S}$ codes is calculated using the following formula $\varepsilon_{r}=\left(\rho_{\mathrm{SART}}-\rho_{6 \mathrm{~S}}\right) *$
$100 / \rho_{\text {SART }}$. Figure 6 summarizes the results obtained.

The relative error, in absolute value, between $6 \mathrm{~S}$ and SART codes does not exceed values $7 \%, 6 \%$ and $5 \%$ for solar zenith angles $\theta_{s}=30^{\circ}, 60^{\circ}$ and $80^{\circ}$, respectively.

In the second case, the aerosol atmosphere is considered, thus absorption by gases is ignored. The study is realized for two models of aerosol: urban and biomass burning and for two values of visibility 5 and $20 \mathrm{~km}$. The results obtained are presented in figures $7-10$.

For a biomass burning model (figure 7), the relation between surface and TOA reflectances is almost linear. At $\lambda=1.2$ and $0.9 \mu \mathrm{m}$, surface and TOA reflectances are practically identical (slope of the curves is almost equal to the unit) where the scattering influence of aerosol is generally small. At $\lambda=0.56,0.4$ and $0.7 \mu \mathrm{m}$, the scattering influence increases. Moreover, the difference between surface and TOA reflectances changes the sign with the increase of TOA reflectances. When solar zenith angle equal to $80^{\circ}$, the Mie scattering intervenes 

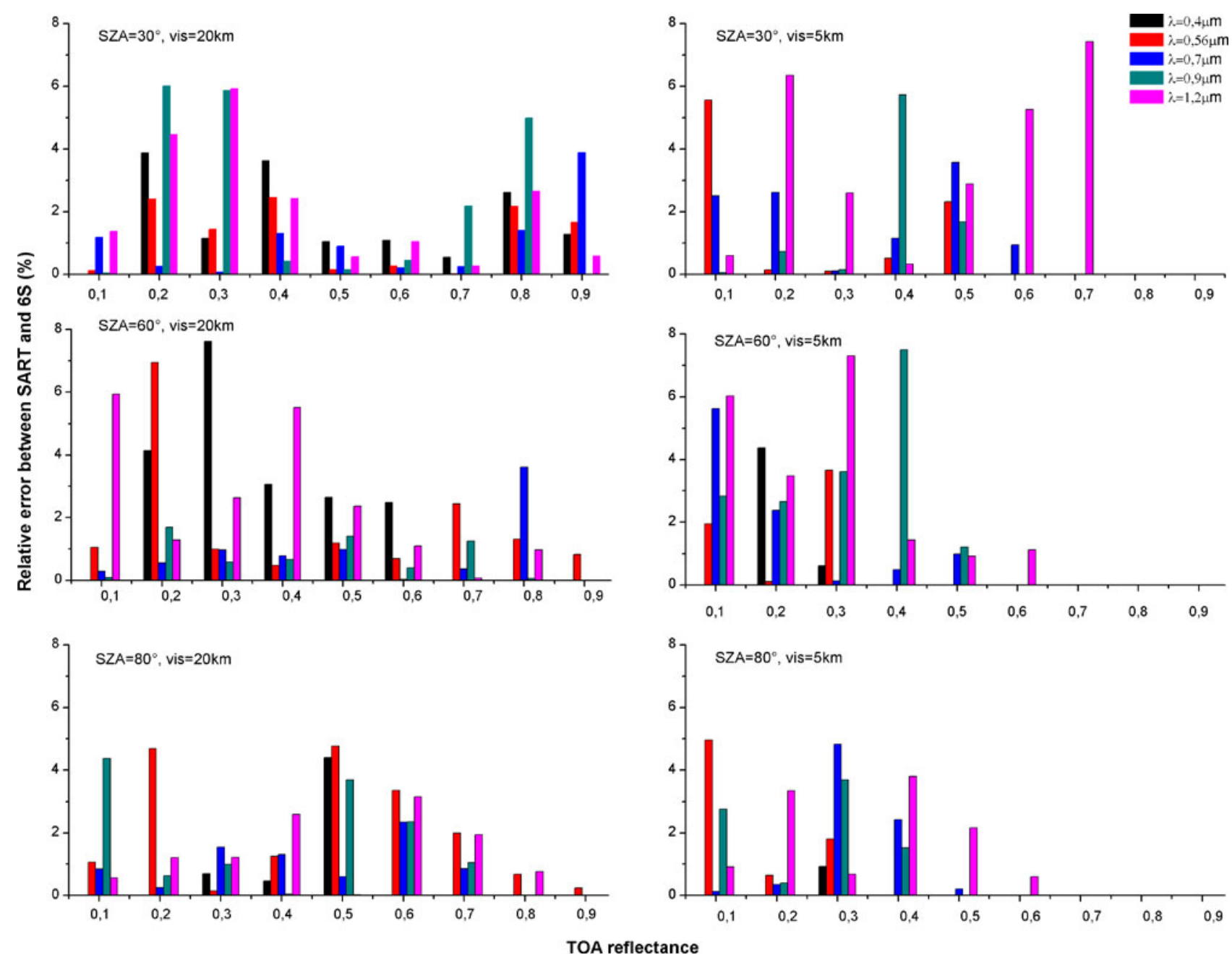

Figure 12. Relative error between reflectances calculated by $6 \mathrm{~S}$ and SART codes for a mixed atmosphere (US standard and urban model).

by increasing the aerosol influence for $\lambda=0.9$ and $1.2 \mu \mathrm{m}$. Consequently, for all wavelengths, the differences between surface and TOA reflectances increase and change sign when TOA reflectances increase.

The relative error (figure 8), in absolute value, between $6 \mathrm{~S}$ and SART codes reach $8 \%$ for the two values of the visibility ( 5 and $20 \mathrm{~km}$ ) and for the two solar zenith angles $30^{\circ}$ and $60^{\circ}$. When $\theta_{s}=80$, the relative error does not exceed $6 \%$.

When VIS $=20 \mathrm{~km}$ (figure 9 ), the aerosol influence of the urban model is intensified for the visible wavelengths $(0.4,0.56$ and $0.7 \mu \mathrm{m})$. This intensity increases with the solar zenith angle, so the surface reflectance converges rapidly as value 1 . At VIS $=5 \mathrm{~km}$, the aerosol influence is even larger. The surface reflectance increases quickly with TOA reflectance for all studied wavelengths. This rise is large as the wavelength is small and the solar zenith angle is large.

Figure 10 shows that the maximum value of relative error, in absolute value, is located between

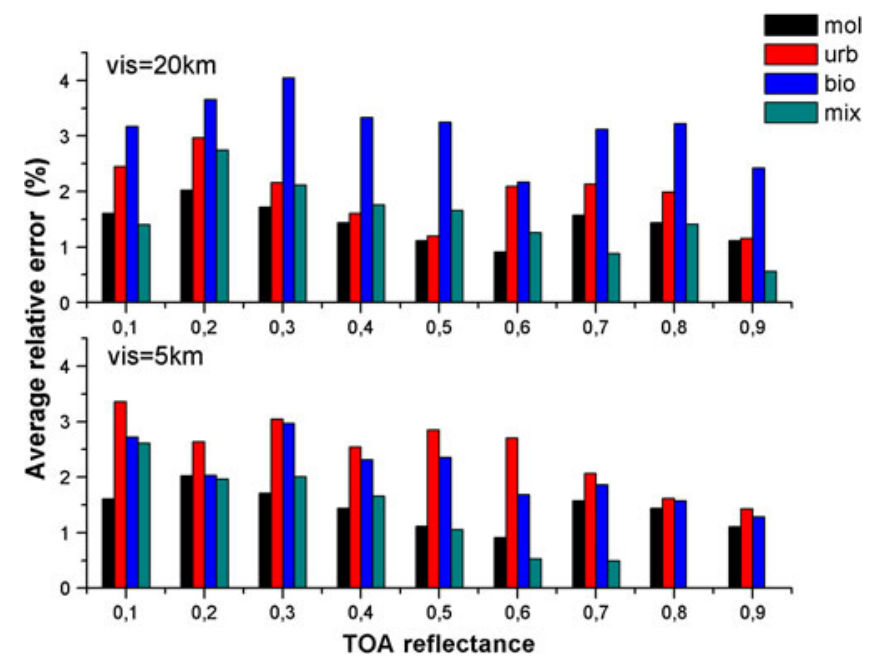

Figure 13. Average relative error between reflectances calculated by $6 \mathrm{~S}$ and SART codes (mol: molecular atmosphere, bio: biomass burning aerosol atmosphere, urb: urban aerosol model, mix: mixed atmosphere). 
$4 \%$ (for $\theta_{s}=80^{\circ}$ and VIS $=20 \mathrm{~km}$ ) and $7 \%$ (for VIS $=5 \mathrm{~km}$ and $\theta_{s}=30^{\circ}$ and $80^{\circ}$ ). The relative error is minimal for surface reflectances close to the value 1 . The last case represents the study performed on a standard US atmosphere with urban aerosol for two values of visibility 5 and $20 \mathrm{~km}$. Figures 11 and 12 summarize the results obtained.

Figure 11 illustrates the aerosol influence observed previously (figure 9). Moreover, the molecular absorption effect contributes to reduce the surface reflectance, except for the wavelength $\lambda=0.9 \mu \mathrm{m}$ because the total transmittance is large. This reduction is perfectly apparent for $\lambda=1.2 \mu \mathrm{m}$.

The relative error (figure 12), in absolute value, is integrated between $6 \%$ and $7 \%$ for the solar zenith angles $\theta_{s}=30^{\circ}$ and $60^{\circ}$, and reach $5 \%$ for $\theta_{s}=80^{\circ}$. For large TOA reflectances, the surface reflectance reach 1 and the relative error between SART and $6 \mathrm{~S}$ codes is practically null.

Figure 13 summarizes the average relative error, calculated over the studied wavelengths and solar zenith angles, for the four models defined previously.

The average relative error, between SART and $6 \mathrm{~S}$ codes, is larger for an aerosol atmosphere than molecular and mixed atmospheres. Moreover, when VIS $=20 \mathrm{~km}$, the error is larger for biomass aerosol model than urban model. Whereas, for VIS $=5 \mathrm{~km}$ the contrary is observed. In general, the average relative error is lower for VIS $=5 \mathrm{~km}$ compared to that for VIS $=20 \mathrm{~km}$.

Table 2. Acquisition dates and weather data of studied images.

\begin{tabular}{llccccc}
\hline Image & \multicolumn{1}{c}{ Satellite } & $\begin{array}{c}\text { Acquisition } \\
\text { date }\end{array}$ & $\begin{array}{c}\text { Temperature } \\
\left({ }^{\circ} \mathrm{C}\right)\end{array}$ & $\begin{array}{c}\text { Pressure } \\
(\mathrm{mb})\end{array}$ & $\begin{array}{c}\text { Humidity } \\
(\%)\end{array}$ & $\begin{array}{c}\text { Visibility } \\
(\mathrm{km})\end{array}$ \\
\hline 1 & LANDSAT-5(TM) & $13 / 02 / 2011$ & 10.6 & 1017.7 & 67 & 9.2 \\
2 & LANDSAT-5(TM) & $01 / 06 / 1999$ & 12.7 & 1010.3 & 34 & 16.1 \\
3 & LANDSAT-7(ETM & \\
4 & SPOT 4 & $03 / 04 / 2011$ & 22.4 & 1020.0 & 26 & 14 \\
\hline
\end{tabular}
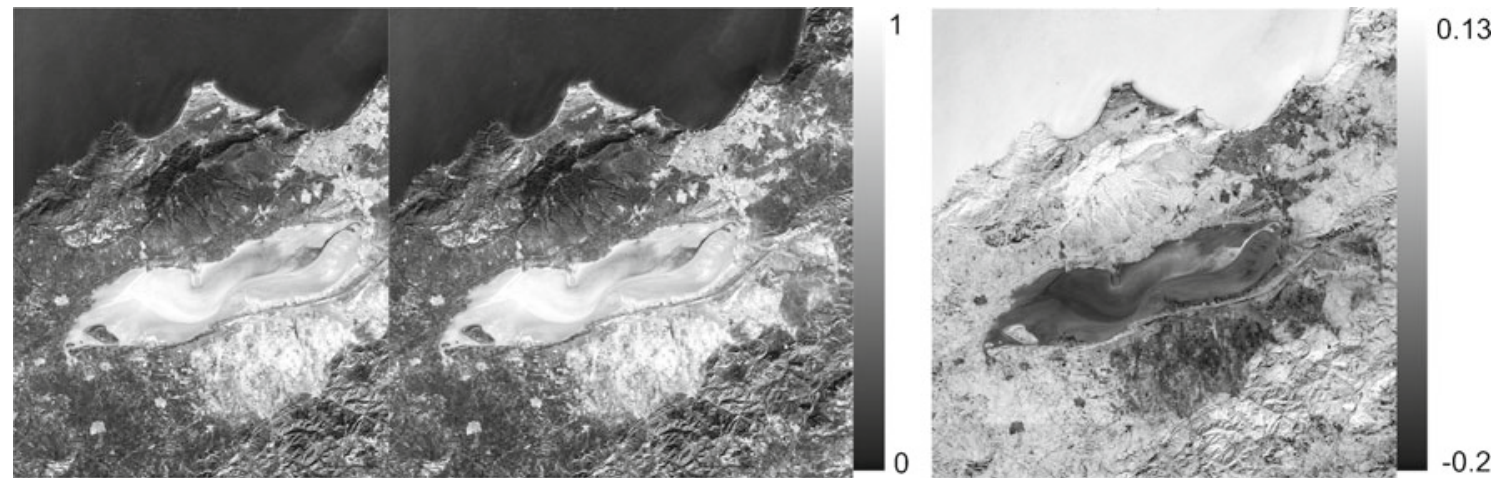

Figure 14. LANDSAT-5 (TM) image (left) before and (centre) after correction and image of the difference (right) (northwest of Algeria, February 13, 2011 at 10:28 h).
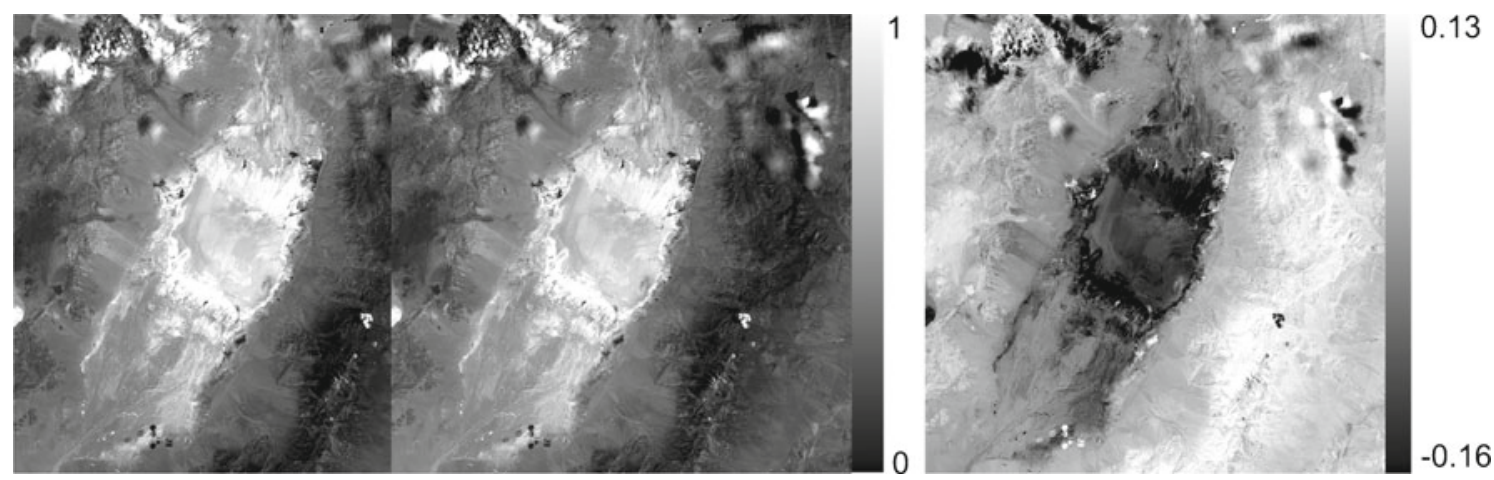

Figure 15. LANDSAT-5 (TM) image (left) before and (centre) after correction and image of the difference (right) (Railroad Valley Playa, Nevada USA, June 6, 1999 at 17:59). 
The difference between SART and $6 \mathrm{~S}$ codes is more reduced for molecular and mixed atmospheres than aerosol atmosphere. This difference is primarily due to the used method (Monte Carlo for SART and successive orders of scattering for $6 \mathrm{~S}$ ). Nevertheless, both codes use the same equations for molecular absorption and scattering processing, which reduces the difference between the two codes. Contrary, the modelling of aerosol scattering in SART, based on the Henyey-Greenstein phase function and the Mie theory, differs from that used in $6 \mathrm{~S}$ where the aerosol optical thickness is calculated beforehand. Consequently, the difference is more significant.

SART code was used to calculate the surface reflectance of several areas using some acquired images LANDSAT and SPOT on various dates. Table 2 presents acquisition dates and weather data of studied images.

The first studied site is the great sabkha of Oran in north Algeria. LANDSAT-5 (TM) image, that covers this region, is used. Raw and corrected images and image of the difference are shown in figure 14.

The great sabkha of Oran, similar to an extended lens with approximately $45 \mathrm{~km}$ of length and a maximum width of $12 \mathrm{~km}$, is located at $15 \mathrm{~km}$ of
Oran town $\left(3532^{\prime} \mathrm{N}, 0048^{\prime} \mathrm{E}\right)$ between two mountains: Murdjadjo in the north and Tessala in the south. It is a closed depression with a surface of $568.70 \mathrm{~km}^{2}$. It is formed by a thin water layer whose level varies according to seasons. However, the water of the sabkha is salted because it is fed by the streams of the watershed.

Railroad Valley Playa is a dry lake with a composition dominated by clay. It is a desert site with no vegetation and aerosol loading is typically low. The overall size of the Playa is approximately $15 \mathrm{~km}$ and it is located in central Nevada $\left(38.504^{\prime} \mathrm{N}\right.$, $115.692^{\prime} \mathrm{W}$ ) between the towns of Ely and Tonopah. Result images are shown in figure 15.

There are many basins of internal drainage, known as Chotts, which fill with water during winter, but dry out and become salt pans in the summer. The largest of these Chotts in Algeria is the Chergui Chott. It is a closed depression of $8555 \mathrm{~km}^{2}$ of surface located in the western north of Algeria $\left(34.49^{\prime} \mathrm{N}, 0.62^{\prime} \mathrm{E}\right)$ and containing permanent and seasonal saline, brackish, and freshwater lakes and pools, as well as hot springs.

LANDSAT-7 (ETM+) image of north Algeria representing Chergui Chott has been used and corrected (figure 16). However, the primary scan mirror of LANDSAT-7 is failed on May 31, 2003.
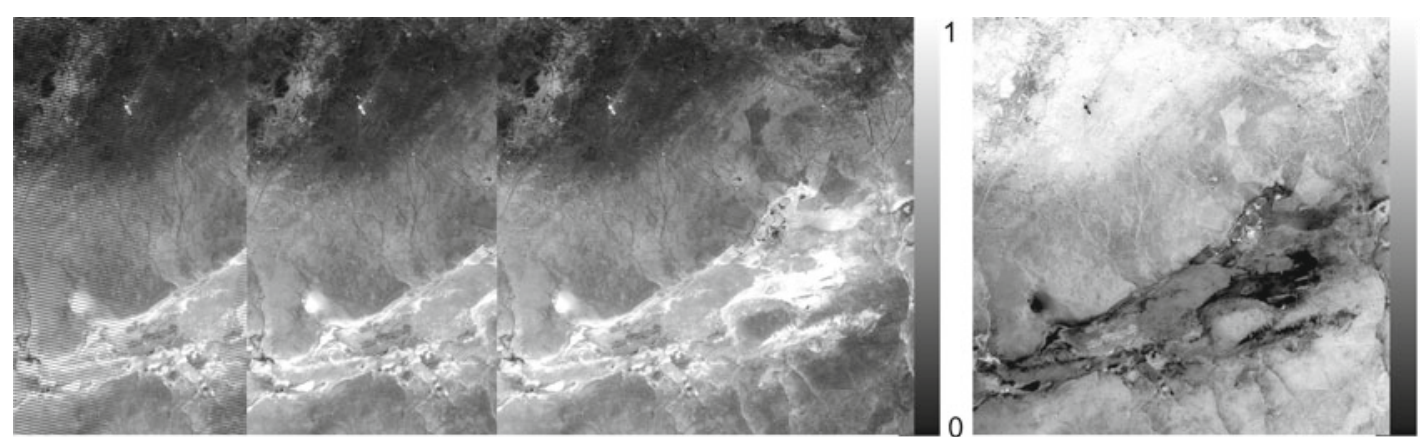

0.18

Figure 16. LANDSAT-7 (ETM+) image (left) before and (centre) after correction and image of the difference (right) (Mechria, north-west of Algeria, April 3, 2011 at 10:26).
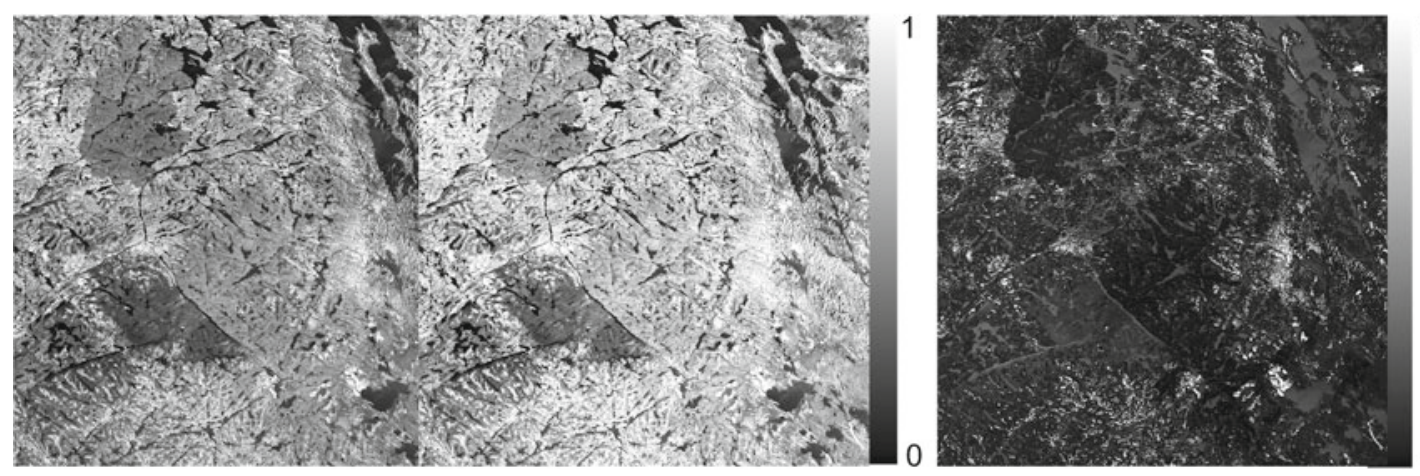

0.55

Figure 17. SPOT 4 image (left) before and (centre) after correction and image of the difference (right) (Quebec, Canada, September 6, 2009 at 15:46). 
Thus, we correct the undersampling of scene before atmospheric correction (figure 16).

Also, the raw and corrected SPOT images of Quebec region in Canada are given in figure 17.

The images of the difference (figures 14-17) illustrate the dissimilarity between the raw and corrected images. Although the atmospheric conditions, and consequently atmospheric reflectance and absorption, are the same ones for all scene, the correction is different because the surfaces, which constitute the scene, are variable. Thus, surfaces with high albedo values (playa, city, etc.) appear darker in the image of the difference than surfaces with low albedo values (sea, vegetation, etc.). The atmospheric correction improves image contrast. Thus, the dark pixels are darker and the

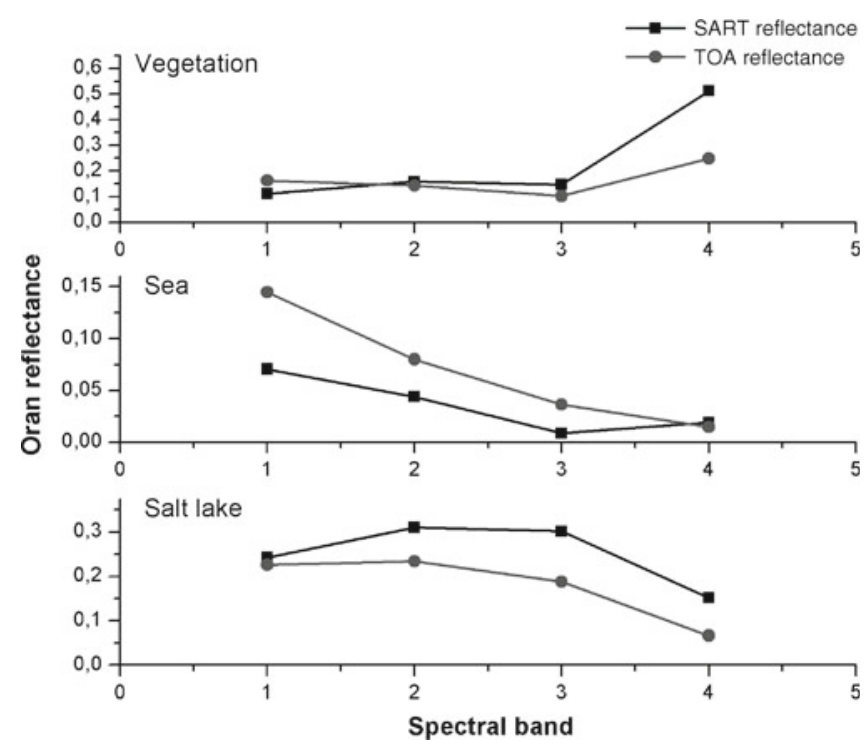

Figure 18. Reflectance of several areas as function as spectral band (great sabkha of Oran).

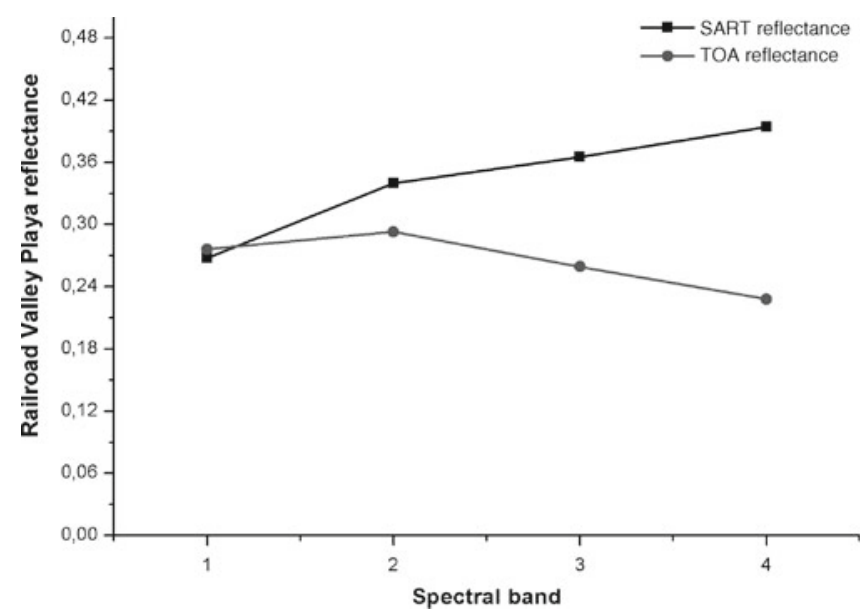

Figure 19. Reflectance of several areas as function as spectral band (Railroad Valley Playa). correction, in this case, is negative (clear zones in the image of difference), and the clear pixels are clearer and the correction is positive (dark zones in the image of the difference). The atmosphere tends to raise the signal resulting from dark surfaces and decrease the signal resulting from clear surfaces. Radiometric values (reflectances) for selected areas representing the sea and the ground from raw and corrected images are shown in figures 18-21 for the visible and near-infrared (NIR) bands.

Each zone (figure 18) is characterized by its own signature: the vegetation has a low reflectance in the red and blue bands, a slightly larger reflectance

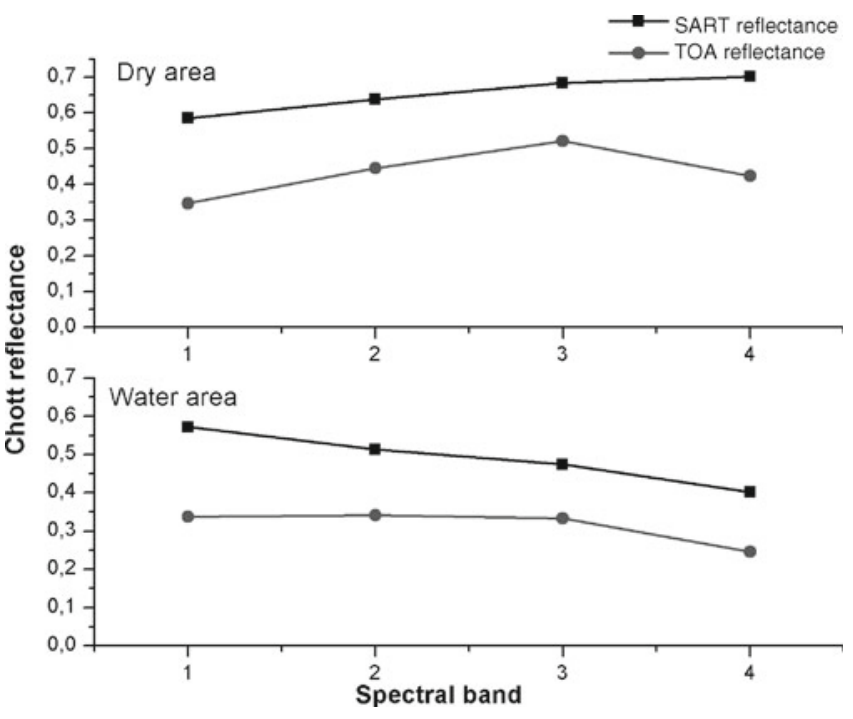

Figure 20. Reflectance of several areas as function as spectral band (Chergui Chott).

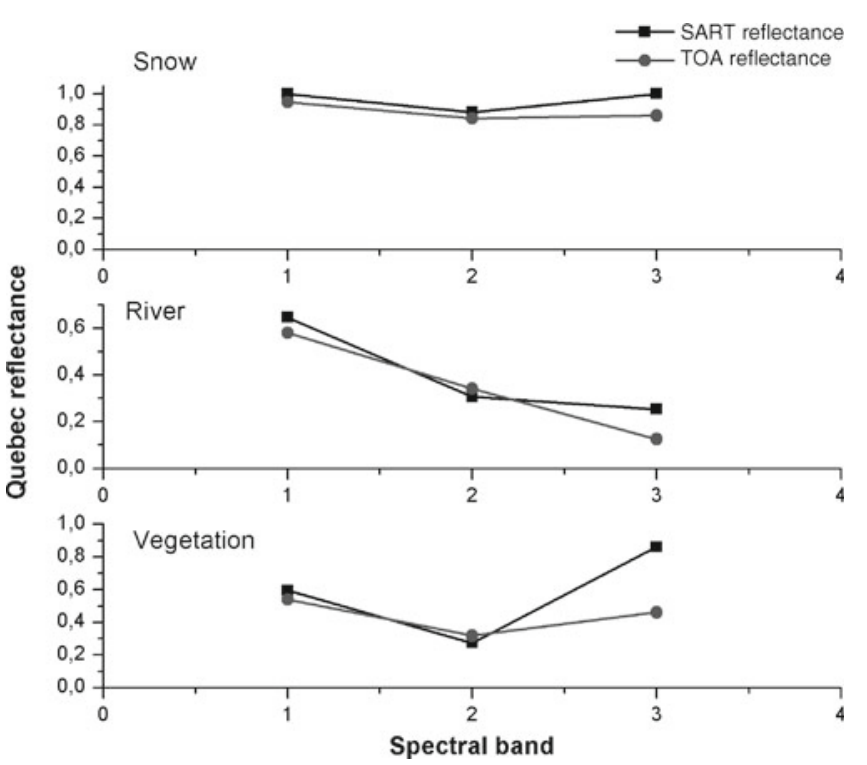

Figure 21. Reflectance of several areas as function as spectral band (Quebec). 
in the green band and a strong reflectance in the near-infrared band. The sea is characterized by a higher reflectance in blue than in the red and the near-infrared. The sabkha, in the dry zone, has a reflectance which grows slightly with the wavelength because this soil is formed by clay and sand mixture with salt deposits due to the draining of the sabkha salted water. However, the water zone is characterized by a weak reflectance reduction in the red band and a very low reflectance in the near infra-red.

The ground of playa (figure 19) is characterized by a slight increase of the reflectance with the wavelength. It is spatially homogeneous with a composition consisting of compacted clay-rich lacustrine deposits forming a relatively smooth surface. However, the surface suffer from the presence of iron absorption $(\mathrm{Fe} 3+)$ in the visible part of the spectrum, characteristic of playas in this region (Chander 2009).

The following table (table 3) illustrates a comparison between the results obtained by SART and those measured by Thome for the acquired image of the Railroad Valley Playa on June 1, 1999 (Thome 2001).

The relative error, in absolute value, varies between $0.04 \%$ and $5.43 \%$.

The chott reflectance (figure 20) is comparable to that of the sabkha and playa. It increases with the wavelength in the dry area and decreases when the wavelength increases in the water area.

The SPOT image consists of several different zones. The snow zone is characterized by a strong reflectance in the first three bands of the SPOT satellite. The vegetation reflectance is high in the green and near-infrared bands and decreases in the

Table 3. A comparison with reflectances calculated by SART and Thome.

\begin{tabular}{lllll}
\hline & Band 1 & Band 2 & Band 3 & Band 4 \\
\hline SART reflectance & 0.6754 & 0.3397 & 0.3651 & 0.3939 \\
Surface reflectance & 0.253 & 0.332 & 0.365 & 0.393 \\
Relative error (\%) & 5.4375 & 2.2828 & 0.0399 & 0.25 \\
\hline
\end{tabular}

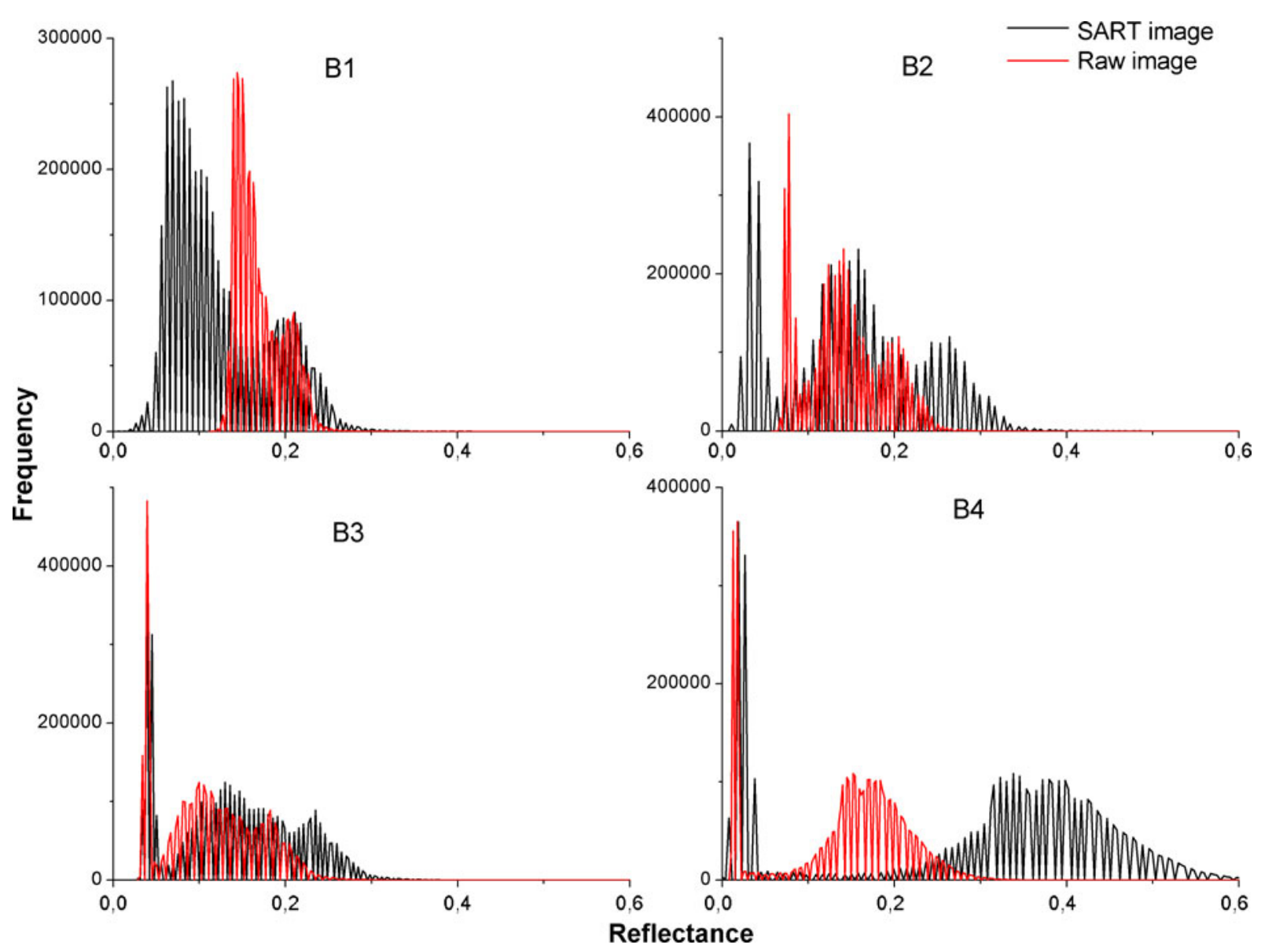

Figure 22. Histograms of image 1 (band 1, 2, 3 and 4). 
red band. The black zones of the image represent the rivers characterized by a decreasing reflectance with the wavelength (figure 21). Finally, for example and to visualize the differences between raw and corrected images, histograms for different bands of LANDSAT-5 image of Oran region were plotted in figure 22.

After correction, the histograms of the four bands become more extended, which means that the images are contrasted. The blue band histogram (B1) is composed of a large peak in the interval $[0.05,0.1]$ which represents the vegetation and the sea and a second smaller peak representing the salt lake of Oran.

On the other hand, the histograms of the green and red bands (B2 and B3) are tri-modal. The radiometric distribution of the values represents three spaced population: sea, characterized by peaks of values 0.05 in the green and 0.02 in the red, the vegetation represented by the interval $[0.1,0.2]$ in the green band and $[0.05,0.25]$ in the red band and the salt lake and its environs whose reflectance exceeds value 0.25 in the green and red bands.

The histogram of the near-infrared band (B4) is bimodal, the two modes, representing the sea and the vegetation, are perfectly distinct. The salt lake is represented by short frequencies corresponding to the pixel numbers whose reflectances vary between 0.05 and 0.25 .

\section{Conclusion}

In this study, a new atmospheric correction code for remote sensing images has been developed, where a radiative transfer model adapted for the spherical atmosphere has been implemented and whose fundamental basis lies on the estimation of geometric and atmospheric parameters namely the extinction and scattering coefficients of aerosols and molecules. The molecular coefficients are sought once the atmospheric temperature and pressure profiles are defined. However, the aerosol coefficients are obtained by resolving Mie equation. This will set the stage for a comprehensive characterization of the atmospheric state prior to the image acquisition on one hand. On the other hand, the tracking of each generated photon is done by using Rayleigh and Henyey-Greenstein phase functions to sample scattering angles, besides that, use is made of extinction coefficients to determine simple diffusion albedo and scattering probability for aerosols. SART uses simplest algorithms of the Monte Carlo method (rejection method, numerical inversion, discrete variables generation) based on the random sampling, which is an advantage when we do not have much information of the studied medium. Thus, for the atmosphere, the Monte Carlo method makes it possible to simulate, arbitrarily, the optical thickness (representing absorption and scattering) for each photon between two interactions that allows to treat simultaneously the absorption and scattering processes. Moreover, Monte Carlo method permits to simulate photon interaction with the atmosphere components and, as a result, to build a trajectory for each photon (downward and upward ways) in an acceptable computing time (18 s for 1,000,000 of photons generated for all the studied scene).

A comparative study related to the surface reflectance was conducted using SART and $6 \mathrm{~S}$ codes, where a slight discrepancy was observed for the three studied cases. This difference can be explained by the fact that different methods are being used by the two codes, namely Monte Carlo for SART code and successive orders of scattering for the $6 \mathrm{~S}$ code. Moreover, the methods used to calculate the input parameters (geometric and atmospheric) are different too.

To put to test this model, the atmospheric correction SART code was used to implement four images of three satellites: LANDSAT-5, LANDSAT-7 and SPOT. Images of the difference show a significant change even though it is not visible at first glance. These changes were confirmed by raw and corrected reflectance curves for different sites in each image.

As a final remark we can say that this study was, as a final remark, limited to the atmospheric effect on remote sensing images and will be complemented by a study that takes into account ground and environment effects leading to a realistic image correction.

\section{References}

Ahern F J, Goodenough D G, Jain S C, Rao V R and Rochon G 1977 Use of clear lakes as standard reflectors for atmospheric measurements; In: Eleventh International Symposium on Remote Sensing of Environment, Ann Arbor, MI: Environmental Research Institute of Michigan, pp. 583-594.

Badescu V (ed.) 2008 Modeling solar radiation at the Earth's surface: Recent advances (Berlin, Heidelberg: SpringerVerlag), 537p.

Bird R E and Riordan C 1986 Simple solar spectral model for direct and diffuse irradiance on horizontal and tilted planes at the earth's surface for cloudless atmospheres; J. Climate Appl. Meteorol. 25 87-97.

Bonn F J, Collet C, Caloz R and et Rochon G 2001 Précis de télédétection: Traitements numériques d'images de télédétection; Association des universités partiellement ou entièrement de langue française, UREF, Agence universitaire de la francophonie, PUQ, 160p.

Capderou M 2005 Satellites: Orbits and Missions (France: Springer-Verlag), 544p.

Carr S B 2005 The aerosol models in MODTRAN: Incorporating selected measurements from northern Australia, 
Intelligence, Surveillance and Reconnaissance Division, Defence Science and Technology Organisation, DSTOTR-1803, 67p.

Centre d'Etudes Spatiales de la BIOsphère (CESBIO) 2007 Principes Physique de DART, référence DART Handbook, Associated Industrial Company: Magellium, 70p.

Chami M, Santer R and Dilligeard E 2001 Radiative transfer model for the computation of radiance and polarization in an ocean-atmosphere system: Polarization properties of suspended matter for remote sensing; Appl. Opt. 40(15) 2398-2416.

Chander G 2009 Questionnaire for information regarding the CEOS WGCV IVOS subgroup Cal/Val test sites for land imager radiometric gain, Version 1.1, CEOS, 25p.

Chander G, Markham B L and Helder D L 2009 Summary of current radiometric calibration coefficients for Landsat MSS, TM, ETM+, and EO-1 ALI sensors; Remote Sens. Environ. 113 893-903.

Chavez P S Jr 1989 Radiometric calibration of Landsat Thematic Mapper multispectral images; Photogram. Eng. Rem. Sens. 55(9) 1285-1294.

Fraser R S, Ferrare R A, Kaufman Y J, Markham B L and Mattoo S 1992 Algorithm for atmospheric corrections of aircraft and satellite imagery; Int. J. Remote Sens. 13(3) 541-557.

Gascon F 2001 Modélisation Physique d'Images de Télédétection Optique; Thèse de doctorat, université de Toulouse III, discipline: signaux, images et acoustique, $174 \mathrm{p}$

Gueymard C 1995 SMARTS2, Simple Model of the Atmospheric Radiative Transfer of Sunshine: Algorithms and Performance Assessment; Rep. FSEC-PF-270-95, Florida Solar Energy Center, Cocoa, FL, 84p.

Gueymard C A and Kambezidis H D 1997 Solar radiation and daylight models; In: Solar Spectral Radiation, Elsevier Butterworth-Heinemann, Linacre House, Jordan Hill, Oxford OX2 8DP, pp. 221-301.

Hadjit H 2007 Résolution par la Méthode Monte Carlo des Problèmes de Transfert Radiatif dans une Atmosphère Sphérique, thèse de Magister, université de science et de la technologie d'Oran, 127p.

Hall F G, Strebel D E, Nickeson J E and Goetz S J 1991 Radiometric rectification: Toward a common radiometric response among multidate, multisensor images; Remote Sens. Environ. 35 11-27.

Hinds W C 1998 Aerosol technology: Properties, behavior, and measurement of airborne particles, 2nd edn, A WileyInterscience Publication, John Wiley \& Sons, INC., 200p.

Iqbal M 1983 An introduction to solar radiation; Academic Press, Toronto.

Kaufman J Y and Sendra C 1988 Algorithm for automatic atmospheric corrections to visible and near-IR satellite imagery; Int. J. Remote Sens. 9(8) 1357-1381.

Kokhanovsky A A 2008 Aerosol optics: Light absorption and scattering by particles in the atmosphere; Springer-Praxis books in Environmental Sciences, 154p.
Kondratyev K Y A 1969 Radiation in the atmosphere, Volume 12, Academic Press, INC, 929p.

Koschmieder H 1924 Theorie der horizontalen Sichtweite; Beitr. Phys. Atmos. 12 33-53.

Koussa M, Malek A and Haddadi M 2006 Validation de quelques modèles de reconstitution des éclairements dus au rayonnement solaire direct, diffus et global par ciel clair; Revue des Energies Renouvelables $\mathbf{9 N ^ { \circ }} \mathbf{4} 307-332$.

Leckner B 1978 The spectral distribution of solar radiation at the earth's surface - elements of a model; Solar Energy $20143-150$.

Liang S 2004 Quantitative remote sensing of land surfaces, John Wiley \& Sons, Inc., 562p.

Liou K N 2002 An introduction to atmospheric radiation, 2nd edn, Academic Press, An imprint of Elsevier Science, $599 \mathrm{p}$.

Marchuk G I and Mikhailov G A 1980 The Monte Carlo methods in atmospheric optics; Springer series in optical sciences, 210p.

Psiloglou B E, Santamouris M and Asimakopoulos D N 2000 Atmospheric broadband model for computation of solar radiation at the earth's surface: Application to mediterranean climate, Birkhauser Verlag, Basel; Pure Appl. Geophys. 157 829-860.

Rees W G 2001 Physical principles of remote sensing; 2nd edn, Cambridge University Press, 369p.

Richter R 1996 A spatially adaptive fast atmospheric correction algorithm; Int. J. Remote Sens. 17 1201-1214.

Schowengerdt R A 2007 Remote sensing: Models and methods for image processing, 3rd edn, Academic Press, An imprint of Elsevier Science, 558p.

Shettle E P and Fenn R W 1979 Models for the Aerosols of the lower atmosphere and the effects of humidity on their optical properties, Optical Physics Division, Project 7670, Air Force Geophysics Laboratory, Air Force Systems Command, Usaf, 94p.

Tanre D, Deschamps P Y, Devaux C and Herman M 1988 Estimation of Saharan aerosol optical thickness from blurring effects in Thematic Mapper data; J. Geophys. Res. 93 15,955-15,964.

Teillet P M and Fedosejevs G 1995 On the dark target approach to atmospheric correction of remotely sensed data; Canadian J. Remote Sens. 21(4) 374-387.

Thomas G E and Stamnes K 1999 Radiative Transfer in the Atmosphere and Ocean, Cambridge Atmospheric and Space Science Series, Cambridge University Press, 540p.

Thome K J 2001 Absolute radiometric calibration of Landsat $7 \mathrm{ETM}+$ using the reflectance-based method; Remote Sens. Environ. 78 27-38.

Van Heuklon T K 1979 Estimating atmospheric ozone for solar radiation models; Solar Energy 22 63-68.

Vermote E, Tanré D, Deuzé J L, Herman M and Morcrette J 1997 Second Simulation of the Satellite Signal in the Solar Spectrum (6S), 6S User Guide Version 2, Formerly affiliated to Laboratoire d'Optique Atmosphérique, part 2, 83p 